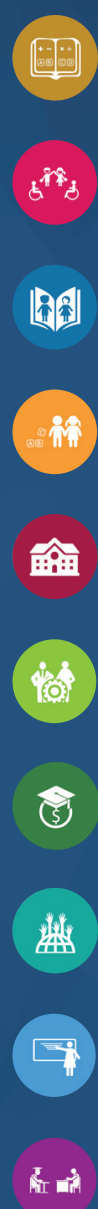

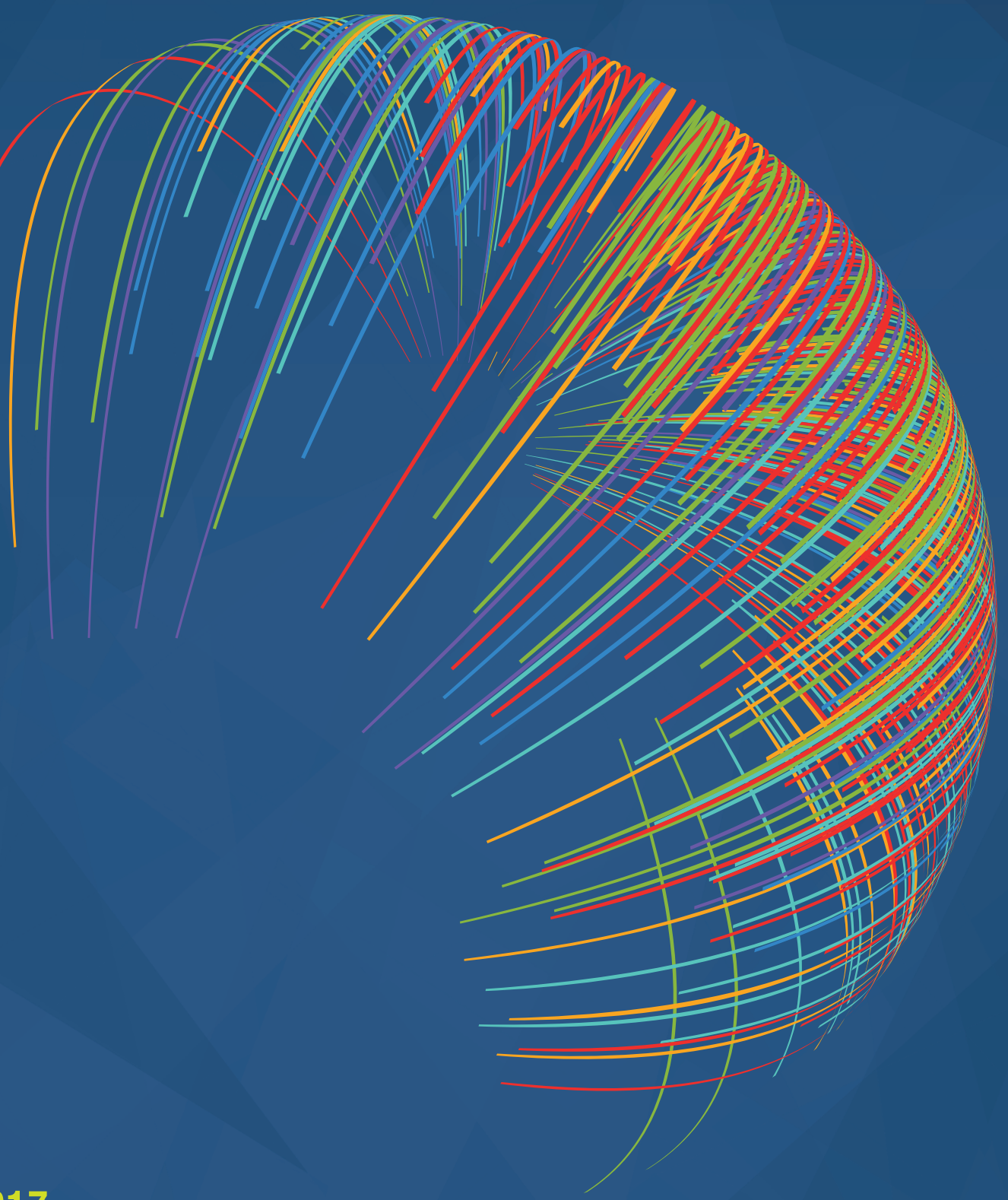

SDG 4 DATA DIGEST 2017

\title{
The Quality Factor: Strengthening National Data to Monitor Sustainable Development Goal 4
}

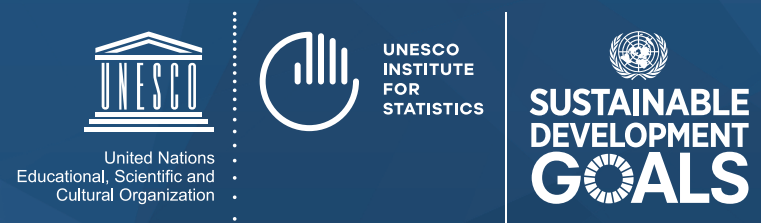



SDG 4 DATA DIGEST 2017

\section{The Quality Factor: Strengthening National Data to Monitor Sustainable Development Goal 4}

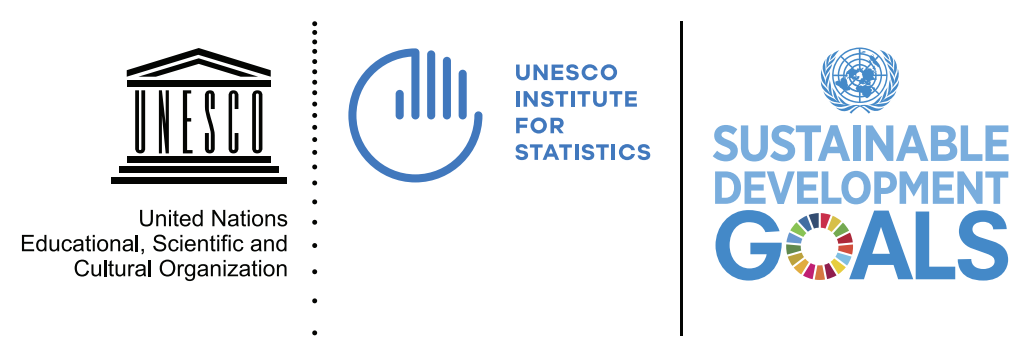




\section{UNESCO}

The constitution of the United Nations Educational, Scientific and Cultural Organization (UNESCO) was adopted by 20 countries at the London Conference in November 1945 and entered into effect on 4 November 1946. The Organization currently has 195 Member States and 10 Associate Members.

The main objective of UNESCO is to contribute to peace and security in the world by promoting collaboration among nations through education, science, culture and communication in order to foster universal respect for justice, the rule of law, and the human rights and fundamental freedoms that are affirmed for the peoples of the world, witwhout distinction of race, sex, language or religion, by the Charter of the United Nations.

To fulfil its mandate, UNESCO performs five principal functions: 1) prospective studies on education, science, culture and communication for tomorrow's world; 2) the advancement, transfer and sharing of knowledge through research, training and teaching activities; 3) standard-setting actions for the preparation and adoption of internal instruments and statutory recommendations; 4) expertise through technical cooperation to Member States for their development policies and projects; and 5) the exchange of specialized information.

\section{UNESCO Institute for Statistics}

The UNESCO Institute for Statistics (UIS) is the official source of cross-nationally comparable data used to monitor progress towards the Sustainable Development Goal for education (SDG 4) and key targets related to science and culture. As confirmed in the Education 2030 Framework for Action, the UIS has the mandate to "work with partners to develop new indicators, statistical approaches and monitoring tools to better assess progress across targets related to UNESCO's mandate".

The UIS was established in 1999. It was created to improve UNESCO's statistical programme and to develop and deliver the timely, accurate and policy-relevant statistics needed in today's increasingly complex and rapidly changing social, political and economic environments.

Published in 2017 by:

UNESCO Institute for Statistics

P.O. Box 6128, Succursale Centre-Ville

Montreal, Quebec H3C 3J7 Canada

Tel: +1 514-343-6880

Email: uis.publications@unesco.org

http://www.uis.unesco.org

ISBN 978-92-9189-217-4

Ref: UIS/2017/ED/SD/11

(C) UNESCO-UIS 2017

Design: JCNicholls Design / www.jcnicholls.com

This publication is available in Open Access under the Attribution-ShareAlike 3.0 IG0 (CC-BY-SA 3.0 IG0) license (http://creativecommons.org/ licenses/by-sa/3.0/igo/). By using the content of this publication, the users accept to be bound by the terms of use of the UNESCO Open Access Repository (http://www.unesco.org/open-access/terms-use-ccbysa-en).

The designations employed and the presentation of material throughout this publication do not imply the expression of any opinion whatsoever on the part of UNESCO concerning the legal status of any country, territory, city or area or of its authorities or concerning the delimitation of its frontiers or boundaries.

The ideas and opinions expressed in this publication are those of the authors; they are not necessarily those of UNESCO and do not commit the Organization. 


\section{Table of contents}

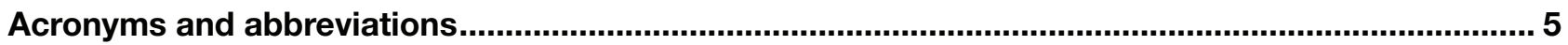

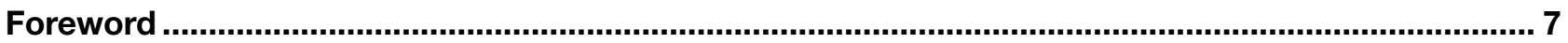

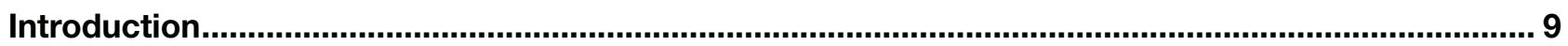

1. Monitoring the international education agenda ........................................................................ 10

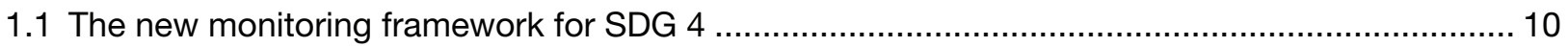

1.2 The development and implementation of global and thematic indicator frameworks for SDG 4 .. 13

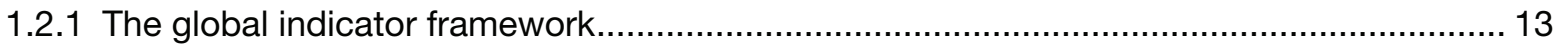

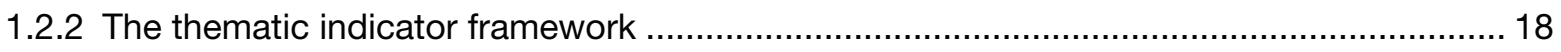

1.3 The challenge of producing the required data for the indicators .............................................. 19

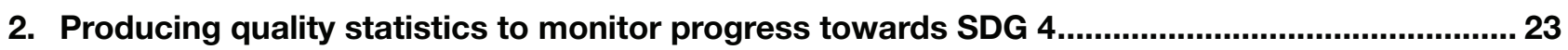

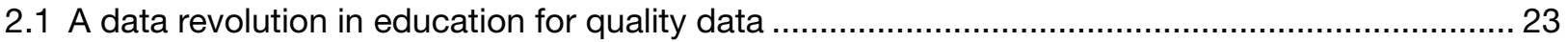

2.2 Producing education data at the national level according to quality standards .......................... 27

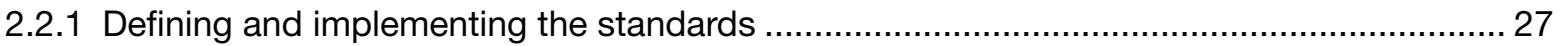

2.2.2 Using data quality assessment frameworks with national education statistics .................. 30

2.3 Producing quality SDG 4 indicators for global monitoring frameworks.................................... 34

2.3.1 Development of international definitions and standards for producing SDG 4 indicators... 36

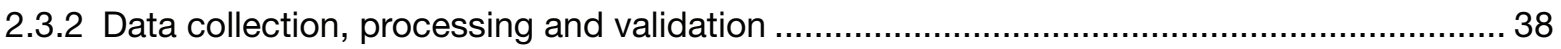

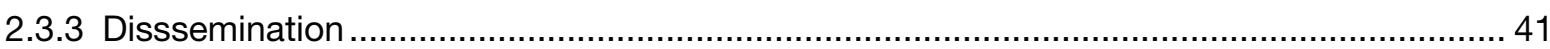

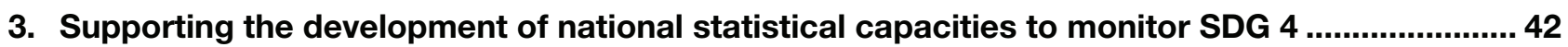

3.1 Designing and implementing a National Strategy for the Development of Education

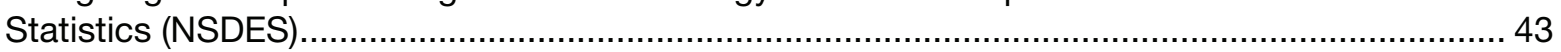

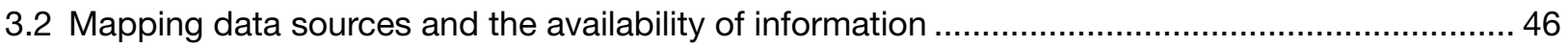

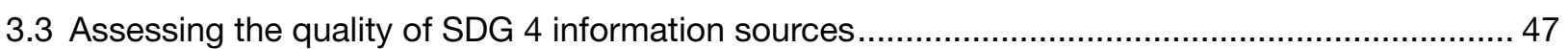

3.3.1 Data quality analysis of administrative routine systems .............................................. 48

3.3.2 Data quality analysis of sources for government education expenditure data ................... 49

3.3.3 Data quality analysis of education household surveys ................................................... 50

3.3.4 Data quality analysis of learning outcomes assessments.............................................. 51

3.4 Towards a coordinated approach to education data production.............................................. 52

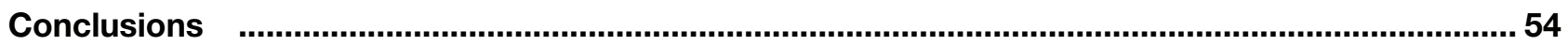

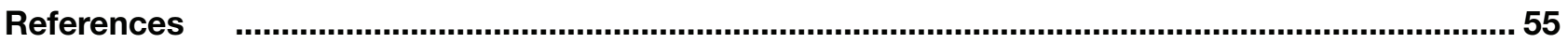

Annex 1. UIS Code of Practice for education statistics: Principles and indicators ...............................59

Annex 2. Links between the UIS Code of Practice for education statistics and the UN National

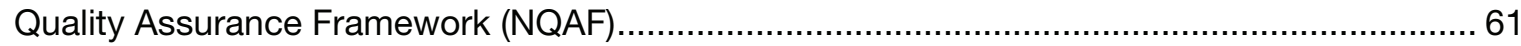

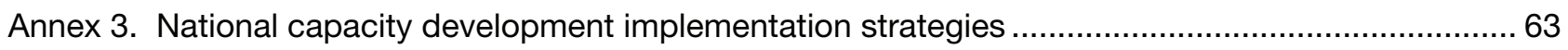

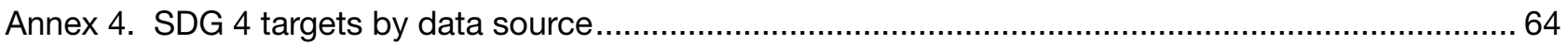

Annex 5. Twelve main questions to assess the data quality of government financial systems ............... 65 


\section{List of tables}

Table 1. The current status of global and thematic indicators to monitor SDG 4 ................................ 14

Table 2. Extract of the Results Reporting Template for the SDG 4 data mapping questionnaire ............. 47

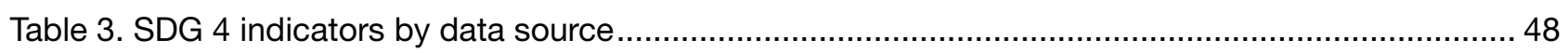

\section{List of figures}

Figure 1. Four levels of monitoring education targets ................................................................. 11

Figure 2. SDG 4 global and thematic indicator availability in the UIS database, June 2017 .................. 20

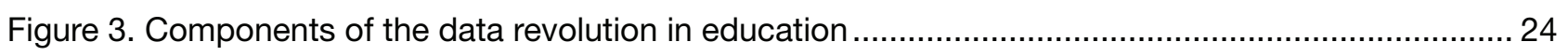

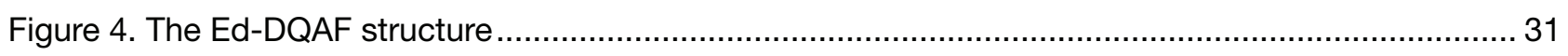

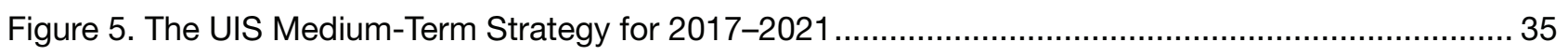

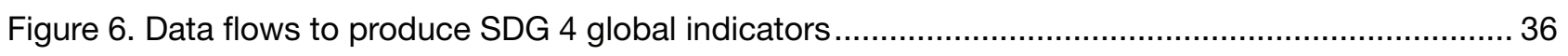

Figure 7. Quality assurance in UIS data collection, processing and validation ..................................... 39

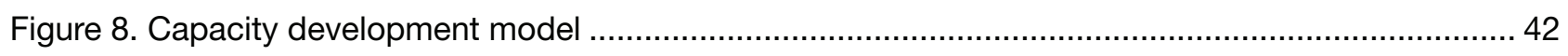

Figure 9. Organization of National Strategies for the Development of Statistics (NSDS) ....................... 44

Figure 10. UIS components to support national education data production and tools ........................... 53

\section{List of boxes}

Box 1. Categorisation of SDG 4 global indicators by IAEG-SDGs tiers............................................. 17

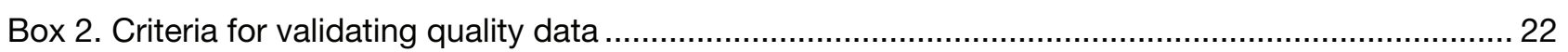

Box 3. A code of good practice in statistics for Latin America and the Caribbean ............................... 26

Box 4. The United Nations National Quality Assurance Framework (NQAF) and the United Nations Statistical Quality Assurance Framework (UN SQAF) ............................................................ 26

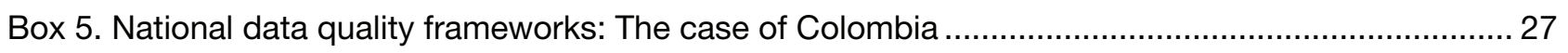

Box 6. The 12 principles of the Code of Practice for education statistics ............................................ 29

Box 7. Checklists used during quality assessments: The example of Principle 8 .................................. 33

Box 8. The International Standard Classification of Education (ISCED) …......................................... 37

Box 9. Challenges in producing indicators on learning outcomes..................................................... 40

Box 10. Monitoring national education sector plans.................................................................... 46

Box 11. The UIS light version of the Ed-DQAF and CoP for routine administrative data systems ........... 49 


\title{
Acronyms and abbreviations
}

\author{
ACER Australian Council for Educational Research \\ BREDA Bureau Régional pour l'éducation en Afrique (now UNESCO Regional Office in Dakar) \\ CapED Capacity Development for Education Programme (UNESCO) \\ CCS-UNS Committee of the Chief Statisticians of the United Nations System \\ CoP Code of Practice \\ CSO Civil society organization \\ DANE Departamento Administrativo National de Estadística (National Department of Statistics) \\ DHS Demographic and Health Survey \\ DFAT Department of Foreign Affairs and Trade (Australia) \\ DQAF Data Quality Assessment Framework \\ ECLAC Economic Commission for Latin America and the Caribbean \\ ECOSOC United Nations Economic and Social Council \\ ED 2030 SC Education 2030 Steering Committee \\ Ed-DQAF Education Data Quality Assessment Framework \\ EFA Education for All \\ EMIS Education Management Information System \\ ESS European Statistical System \\ EU European Union \\ FAO Food and Agriculture Organization of the United Nations \\ GAML Global Alliance to Monitor Learning \\ GDP gross domestic product \\ GEM Report Global Education Monitoring Report \\ GPE Global Partnership for Education \\ GP LA Principles of Good Practice in Learning Assessment \\ HHS household survey \\ HLPF High-Level Political Forum on Sustainable Development \\ HLG-PCCB High-Level Group for Partnership, Coordination and Capacity Building for statistics for the \\ 2030 Agenda for Sustainable Development \\ IAEG-SDGs Inter-Agency Expert Group on SDG indicators \\ ICT information and communications technology \\ IPUMS Integrated Public Use Microdata Series-International \\ IMF International Monetary Fund \\ ISCED International Standard Classification of Education \\ LaNA Literacy and Numeracy Assessment \\ MDG Millennium Development Goal \\ MICS Multiple Indicator Cluster Survey
}




\begin{tabular}{|c|c|}
\hline NEGED & National Expert Group on Education Data \\
\hline NESS & National Education Statistical System \\
\hline NIF & National Indicator Framework \\
\hline NQAF & National Quality Assurance Framework \\
\hline NSDES & National Strategy for the Development of Education Statistics \\
\hline NSDS & National Strategies to Develop Statistics \\
\hline OECD & Organisation for Economic Co-operation and Development \\
\hline Paris21 & Partnership in Statistics for Development in the 21st Century \\
\hline PASEC & Programme d'analyse des systèmes éducatifs de la CONFEMEN \\
\hline PILNA & Pacific Islands Literacy and Numeracy Assessment \\
\hline PIRLS & Progress in International Reading Literacy Study \\
\hline PISA & Programme for International Student Assessment \\
\hline QAF & Quality Assurance Framework \\
\hline RSDS & Regional Strategies for the Development of Statistics \\
\hline SACMEQ & Southern and Eastern Africa Consortium for Monitoring Educational Quality \\
\hline SADC & Southern African Development Community \\
\hline SCA-ECLAC & $\begin{array}{l}\text { Statistical Conference of the Americas of the Economic Commission for Latin America and } \\
\text { the Caribbean }\end{array}$ \\
\hline SDG & Sustainable Development Goal \\
\hline SDMX & Statistical Data and Metadata Exchange \\
\hline SEA PLM & Southeast Asia Primary Learning Metrics \\
\hline TAG & Technical Advisory Group on Post-2015 Education Indicators \\
\hline TCG & Technical Cooperation Group on the SDG 4-Education 2030 Indicators \\
\hline TERCE & Tercer Estudio Regional Comparativo y Explicativo \\
\hline TIMSS & Trends in International Mathematics and Science Study \\
\hline UIS & UNESCO Institute for Statistics \\
\hline UN & United Nations \\
\hline UNDESA & United Nations Department of Economic and Social Affairs \\
\hline UNDP & United Nations Development Programme \\
\hline UNESCO & United Nations Educational, Scientific and Cultural Organization \\
\hline UNGA & United Nations General Assembly \\
\hline UNICEF & United Nations Children's Fund \\
\hline UNSC & United Nations Statistical Commission \\
\hline UNSD & United Nations Statistics Division \\
\hline UN SQAF & United Nations Statistical Quality Assurance Framework \\
\hline WG DRVD & Working Group on Data Reporting, Validation and Dissemination \\
\hline WG ID & Working Group on Indicator Development \\
\hline WG SCB & Working Group on Statistical Capacity Building \\
\hline
\end{tabular}




\section{Foreword}

The Sustainable Development Goals (SDGs) and the Education 2030 Framework for Action set an ambitious agenda for countries to provide access to quality education and effective learning outcomes for all. Across each target, the overarching focus on equity aims to ensure that no one is left behind, especially the poorest and most vulnerable groups. In less than 13 years, the international community must transform this decisive engagement into reality for all children and youth, no matter where they live or the conditions they face.

The experience of the preceding education agenda confirms that the stark reality of implementation undercuts ambition. While access to primary education has increased globally since 2000 , significant improvements to equitable opportunities and quality of learning are still warranted. One critical lesson learned is the value of setting meaningful quantitative measures to monitor the development and implementation of education policies at national and international levels. The increase in the number of education targets and indicators of the SDG 4-Education 2030 Agenda underscores the importance of international education monitoring.

The new education agenda places an unprecedented demand on countries to produce more and better data. Efforts to build stronger and more reliable national statistical systems are already underway in many countries, but the new indicators and level of detail required create significant challenges at the national level. There is an urgent need to improve the quality of data needed to monitor and achieve the SDG 4-Education 2030 Agenda.

This report, The Quality Factor: Strengthening National Data to Monitor Sustainable

Development Goal 4, is the second in the series of the Sustainable Development Data Digest. This volume proposes a conceptual framework and a concrete set of tools to help countries improve the quality of their data and fulfil their reporting requirements.

The previous report, Laying the Foundation to Measure Sustainable Development Goal 4, explained how countries and education experts came together to develop a global compact for education, measured through a list of 43 global and thematic indicators. With regard to data quality, the 2016 Digest provided two cautionary messages. First, despite decades of international cooperation to monitor education, many countries were not adequately prepared to deliver the data, either because SDG 4 indicators did not yet exist or could not be produced in a reliable and regular manner. Second, the quality and international comparability of monitoring indicators directly depend on the quality of national education data, especially when dealing with the complexities of different types of data sources.

This year's report directly addresses these issues by presenting the latest efforts of international working groups and the UNESCO Institute for Statistics (UIS) to help countries implement the global and thematic indicator frameworks. The SDG Digest shows how the Institute's work with countries to strengthen their national education statistical systems for policymaking purposes also lays the foundation for the cross-national comparability needed to monitor progress globally. Based on the results of a series of diagnostic evaluations of data quality and availability, the UIS is helping countries develop their own national strategies to improve their education statistical systems, while strengthening the technical capacities of their national stakeholders. At the international level, the UIS continues to break new ground as part of its mandate to develop the methodologies and standards needed for new indicators.

This work is all part of the UIS vision for a data revolution in education based on three pillars involving the key actors - namely governments, development partners and the UIS. First, we need to create the enabling environments in which communities, governments and civil society can use education data to take action and foster accountability. The second pillar involves the production of high-quality crossnationally-comparable data by supporting the 
methodological and standard-setting work of the UIS, as well its data collection and production activities. The third pillar rests on ongoing efforts to strengthen data dissemination and use by governments, communities and civil society groups.

How can we build these pillars? There is an urgent need for sustainable funding and commitment to ensure that education data take their rightful place as public goods and policy tools. At the national level, governments and donors need to better support the capacities of countries to produce, disseminate and use education data.

It is therefore essential to expand the pool of resources by tapping into new sources of funding, especially in the private sector. For example, it would cost just $0.002 \%$ of the total annual revenues of the 14 biggest I.T. companies to equip countries with the basic technologies they need to collect, process and disseminate education data, according to the UIS paper, "The Data Revolution in Education" (UIS, 2017i).

The international community has clearly recognised the transformative power of data to achieve development goals. The new SDG 4 indicators are seen as investments to ensure effective policymaking and action. The initial costs of developing the statistical tools and support needed by countries are inconsequential in comparison to the savings they will bring in terms of the national education budgets and foreign aid. However, the true benefits of data are most clearly seen when we imagine all children and youth in school and learning.

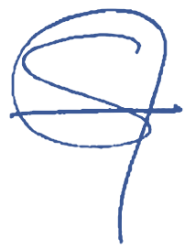

Silvia Montoya

Director 


\section{Introduction}

The new 2030 Agenda for Sustainable Development and its indicator framework set a high standard for national and international information systems. Monitoring the implementation of, and progress towards, the multiple components of the stand alone education goal (Sustainable Development Goal (SDG) 4) requires quality data. Defining the standards of quality data production and assessing the quality of data for this purpose are challenges underlying the national and international monitoring mechanisms already in place. In particular, what changes need to occur and by whom are critical questions to obtaining viable cross nationally-comparable data on education.

During the process of developing indicators and producing data, countries and advisory groups called for transparency and appropriate documentation of statistical processes. The UNESCO Institute for Statistics (UIS) and its partner agencies are major contributors in terms of data collection, indicator development and strengthening of national data systems for quality monitoring of SDG 4. Given the gap between national statistical capacities and the stringent set of expectations for quality data production, the UIS is providing national stakeholders with the methodologies and instruments they need to face the monitoring challenge of the SDG 4 agenda.

This year's edition of the Sustainable Development Data Digest is dedicated to the theme "Quality data to monitor the progress of SDG 4 and statistical capacity development in countries". Section 1 examines the new SDG 4 monitoring framework and defines the global and thematic levels of monitoring education. It takes the reader through recent events and processes that culminated in the development of a proposed selection of 43 indicators - 11 global indicators and 32 thematic indicators - to monitor SDG 4. Within this framework is the need to develop and validate new methodologies and refine existing methodologies to ensure crosscountry comparability. Currently, many countries will struggle to meet the reporting requirements, sending a message of urgency to support capacity building for national data collection efforts for SDG 4.

Section 2 describes the UIS vision for improving the quality of education data at national and international levels. Based on the call for a data revolution, UIS capacity development tools can enable countries to enhance the quality of their national education statistical systems. Data quality assessment frameworks at the national planning level and at the statistical process level serve as diagnostic tools. Sustained and coordinated efforts among international and regional statistical stakeholders are also important to define and validate comparable education data.

Section 3 focuses on the latest activities of the UIS at the national level to build better statistical systems and engage national stakeholders in the ownership and sustainability of their processes. The UIS is working with national statistical systems to take into account education data needs and develop a sector wide approach to education statistics so as to strengthen the quality SDG 4 indicators. To implement this approach, the UIS has developed a set of tools which are adapted for use by national teams to assess the availability of key data and evaluate the quality of the institutional environment, statistical processes and statistical outputs for each existing education information system. 


\section{Monitoring the international education agenda}

In September 2015, 193 Member States of the United Nations (UN) unanimously adopted the 2030 Agenda for Sustainable Development. Building on the Millennium Development Goals (MDGs) approved in 2000, the 2030 Agenda is comprised of 17 Sustainable Development Goals (SDGs) and 169 targets. They are committed to a shared global agenda to end widespread poverty and inequity by improving social and human rights, promoting sustainable economic growth and protecting the environment (UN, 2000, 2015). The associated SDG indicator framework was developed by the Inter-Agency Expert Group on SDG indicators (IAEG-SDGs), a group created by the United Nations Statistical Commission, and adopted by the UN General Assembly in July 2017.

Education is a central theme throughout the 2030 Agenda, which includes a stand alone education goal and education related targets within seven other SDGs (UIS, 2016)..$^{1}$ In particular, SDG 4 is ambitious and aims to "ensure inclusive and equitable quality education and promote lifelong learning opportunities for all" by 2030 . The goal consists of ten targets to guide countries along a transformative path to a sustainable education agenda.

SDG 4 has a broader focus than the MDG Education Goal 2 ("Achieve universal primary education") and expands on the Education for All (EFA) goals adopted by the international education community in Dakar in 2000. ${ }^{2}$ SDG 4 is all encompassing in terms of sub-sector coverage, ranging from early childhood education to lifelong learning. Quality of learning, inclusion and equity are central tenets to achieving the goal. Going beyond education, SDG 4 is also linked with the other goals in terms of acquiring knowledge and skills to promote sustainable development, eliminating gender disparities and expanding access to education to all youth and adults to increase their employment opportunities.

Since September 2015, several processes have begun - or continued in some cases - to work towards the implementation of a coordinated and integrated monitoring framework and the development of the indicators to monitor SDG 4. The first edition of the Sustainable Development Data Digest (2016) documented these efforts, including the selection of monitoring criteria and how key targets and indicators were defined through a country led process guided by experts and advisory groups. This section provides an update to the 2016 Digest discussion on the activities related to the development of the SDG 4 monitoring processes and indicator definitions.

\subsection{The new monitoring framework for SDG 4}

A review of the implementation of the MDG monitoring framework since 2000 has provided lessons for the development of the criteria for monitoring the SDGs. From a statistical perspective, the MDG framework was built on a set of concrete, measurable indicators and generally enabled the improvement of national capacity for statistical monitoring in many developing countries. However, some of the data related challenges that were revealed included the lack of clarity or inconsistencies among goals and indicators, as well as insufficient financial and technical support to improve national monitoring systems. The relationship between global and

\footnotetext{
${ }^{1}$ Other targets related to education are included in SDG 1 (on poverty), SDG 3 (on health and well being), SDG 5 (on gender equality), SDG 8 (on decent work and economic growth), SDG 12 (on responsible consumption and production), SDG 13 (on climate change) and SDG 16 (on peace, justice and strong institutions). See Table 2 in UIS, 2016.

${ }^{2}$ For more information on education related targets and indicators, see the UN Millennium Declaration and the Dakar Framework for Action (UN, 2000; UNESCO, 2000).
} 
national indicators was distorted for some goals, indicators did not sufficiently address inequities among groups, and data quality was subject to discrepancies and differences among data providers (IAEG-MDG, 2013).

In December 2014, UN Secretary-General Ban Ki Moon called for a comprehensive approach to monitoring the SDGs, which was later reflected in the 2030 Agenda's collective and universal call to action (UN, 2015; UNSG, 2014). While he emphasised the importance of effectiveness, efficiency, evidence and universality as guiding principles for reviewing SDG progress, the UN Secretary-General also recommended using a participatory framework in which all stakeholders and related groups (e.g. civil society, business, parliament, academia and government) could recognise their shared responsibility in achieving the SDGs. Figure 1 shows this proposed multi tiered, multi purpose framework composed of four monitoring levels - national, regional, global and thematic - which have the following characteristics:
- National level monitoring of SDG 4 is linked to the needs of national and sub-national governments in developing education sector plans and informing education policies. Data that provide high-level granularity and adapt to the specificities of the national context - such as in sub-national geographical units, specific disadvantaged groups or by wealth - offer a greater capacity to inform policy by examining relevant disparities in education outcomes. Monitoring SDG 4 at this level benefits from the active participation of a diverse group of stakeholders representing their respective constituencies and education related concerns.

- At the regional level of monitoring, a set of indicators may be developed to take account of priorities and issues of common interest that are shared by countries in a particular region, as outlined in regional planning documents or frameworks. Some frameworks are designed to specifically monitor SDGs within a regional policy context. This is the case of the European Union (EU) SDG Indicator Set, which is composed of 100 indicators to monitor the

\section{Figure 1. Four levels of monitoring education targets}

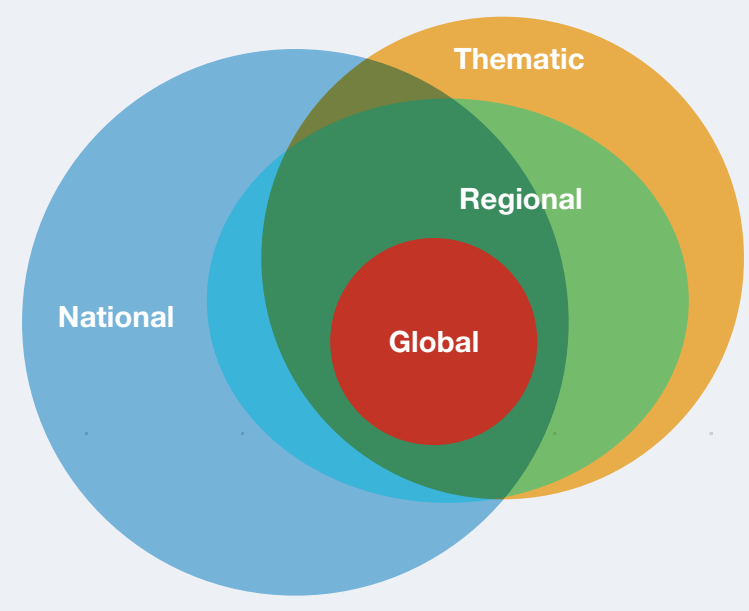

Source: UNESCO Institute for Statistics, 2016. 
17 SDGs. The six regional indicators selected for monitoring SDG 4 have strong links with the Education and Training 2020 strategic framework of the EU, focusing on investing in young people and increasing lifelong learning opportunities (Eurostat, 2017). In a different vein, the African Union developed a broad set of development goals for the region in Agenda 2063: the Africa We Want, with its own set of region specific indicators. Integrating the monitoring systems of Agenda 2063 and the SDGs is part of the ten year implementation plan for national governments (African Union Commission, 2015a, 2015b).

- Global level monitoring relies on a more limited and carefully-selected group of leading indicators to provide an overview of progress towards each target. The harmonisation of monitoring and reporting of SDGs for crosscountry comparability is also of critical importance. The ability to analyse and compare national data across countries and years provides insights into measuring performance, driving policy reform and allocating resources equitably to improve learning among all population groups. The knowledge sharing and universal review is convened annually under the UN's High-Level Political Forum on Sustainable Development (HLPF) (UN, 2017).

- Thematic monitoring adds a level of monitoring of comparable indicators within a specific sector (e.g. education, environment, energy, health) or cross cutting theme (e.g. gender). Thematic indicators serve as a framework to track progress on a cross nationally-comparable basis, with a more in depth view of sectoral priorities than available in the global monitoring framework. Through the agency of the Secretary General, this level provides the opportunity to identify sector specific challenges and bottlenecks and mobilise the action required to address them. The HLPF convenes annual thematic meetings during which it hosts in depth reviews of a cross cutting issue, such as poverty eradication (in 2017), sustainability and resiliency (in 2018) and empowerment, inclusiveness and equality (in 2019) (UNDESA, 2017).

On 4 November 2015, 184 UNESCO Member States adopted the Education 2030 Framework for Action, which provides guidance ("indicative strategies") at national, regional and global levels on how to achieve SDG 4 and how to monitor implementation of each of the ten SDG 4 targets. Education 2030 emphasises that SDG 4 monitoring must include a "multidimensional approach covering system design, inputs, content, processes and outcomes" (UNESCO, 2015, para. 97). It also designates the UNESCO Institute for Statistics (UIS) as the official source of cross nationally-comparable data in education and mandates the Global Education Monitoring Report (GEM Report) to monitor and assess progress in achieving SDG 4 and other education related goals. ${ }^{3}$ National governments have the primary responsibility for building monitoring mechanisms in accordance with the consensus reached at the regional and global levels and in consultation with civil society organizations (CSOs). The document was the result of an 18-month collective effort characterised by numerous regional and national consultations led by governments and civil society. UNESCO and other international partners facilitated this process (UNESCO, 2015).

Included within the Education 2030 Framework for Action is a proposed draft list of 43 thematic indicators - including the 11 global indicators to chart global progress on education. The UIS, together with partner organizations and experts from Member States and civil society, developed this proposal to provide countries with monitoring guidance around a set of educationrelated concepts linked to the global targets. The continued refinement and further development of these indicators into monitoring frameworks are the subject of several processes, described in the following section.

\footnotetext{
${ }^{3}$ The GEM Report, which was launched in 2016, was formerly known as the Education for All Global Monitoring Report.
} 


\subsection{The development and implementation of global and thematic indicator frameworks for SDG 4}

As with the MDGs, progress towards each of the SDGs and their targets needs to be monitored regularly between now and 2030 . Selecting and defining indicators to monitor the global education targets has been a process building on the experience of the MDGs. Assessing progress towards the international goal requires measurement tools which are relevant for analysing the impact of national education policies and for reaching a set of globallycomparable indicators.

\subsubsection{The global indicator framework}

In December 2014, the UN Statistical Commission (UNSC) established an Inter-Agency Expert Group on the SDG indicators (IAEG-SDGs) composed of the Chair of the UNSC and 27 regionally-representative experts from national statistical offices to develop a global indicator framework for all SDGs. ${ }^{4}$ Following several rounds of global consultations and meetings with UN Member States, international and regional organizations, academia, businesses, NGOs and civil society, the IAEG-SDGs first proposed a list of 11 global education indicators to monitor SDG 4 in March 2016, which was ultimately approved at the $48^{\text {th }}$ Session of the UNSC in March 2017 and formally adopted by the UN Economic and Social Council (ECOSOC) and the UN General Assembly (UNGA) in June and July 2017, respectively. ${ }^{5}$ This global monitoring framework for SDG 4 represents the most basic set of indicators considered indispensable for countries to monitor the education goal (see

\section{Table 1).}

With consensus reached on the list of global education indicators, the IAEG-SDGs developed a tier classification tool to identify the state of development of each indicator and its availability on a global scale (see Box 1). Tier 1 and Tier 2 indicators have internationally-established methodologies and standards, although Tier 2 indicators are not regularly produced by countries. Tier 3 indicators require the development of methodologies and standards, and this work has been prioritised by the IAEGSDGs. All indicators are considered equally important for monitoring SDG 4, independent of their tier classification.

The development and validation of new methodologies for Tier 3 global indicators falls under the responsibility of the indicator's custodian and partner agencies. The IAEG-SDGs, which oversees this process, identified three custodian agencies for the global indicators for education. The UIS is the custodian agency for 9 of the 11 SDG 4 global indicators and a partner organization for the remaining two. UNICEF and the Organisation for Economic Co-operation and Development (OECD) are the other two custodian agencies for these global indicators: an indicator related to child development (4.2.1) and an indicator for development assistance for scholarships (4.b.1). ${ }^{6}$

The IAEG-SDGs holds two annual meetings during which it reviews the list of indicators and considers minor changes or refinements from its members or editorial clarifications from the UN Statistics Division (UNSD). ${ }^{7}$ During these meetings, the IAEG-SDGs also assesses the tier classification for groups of selected indicators, examines methodologies proposed by custodian agencies and gives final approval for changes in the tier classification. Based on the outcomes of these annual meetings, the IAEG-SDGs will make recommendations to the UNSC to approve the refinements.

In addition to the annual reviews, the IAEG-SDGs will conduct major quinquennial reviews of the

\footnotetext{
${ }^{4}$ For members, see Box 3 in Section 1.2 in the Sustainable Development Data Digest 2016 (UIS, 2016).

${ }^{5}$ The SDG 4 global indicators were developed by the IAEG-SDGs in a process along with indicators for the other SDGs.

${ }^{6}$ Some education-related indicators are monitored within other Goals, namely SDGs 1, 8, 12, 13 and 16 . Information on the status of those indicators is available on the IAEG-SDGs website https://unstats.un.org/sdgs/iaeg-sdgs/
} 
Table 1. The current status of global and thematic indicators to monitor SDG 4

\begin{tabular}{|c|c|c|c|}
\hline \multirow{2}{*}{\multicolumn{2}{|c|}{ SDG 4 targets }} & \multicolumn{2}{|c|}{ Indicator status } \\
\hline & & $\begin{array}{l}\text { Indicators for } \\
\text { reporting in } 2017\end{array}$ & $\begin{array}{l}\text { Requires further } \\
\text { development }\end{array}$ \\
\hline \multicolumn{4}{|c|}{$\begin{array}{l}\text { Target 4.1 By } 2030 \text {, ensure that all girls and boys complete free, equitable and quality primary and secondary education leading to } \\
\text { relevant and effective learning outcomes }\end{array}$} \\
\hline 4.1.1 & $\begin{array}{l}\text { Proportion of children and young people (a) in Grade } 2 \text { or } 3 \text {; (b) at the end of primary education; } \\
\text { and (c) at the end of lower secondary education achieving at least a minimum proficiency level } \\
\text { in (i) reading and (ii) mathematics, by sex }\end{array}$ & $X$ & $\mathrm{x}$ \\
\hline 4.1 .2 & $\begin{array}{l}\text { Administration of a nationally-representative learning assessment (a) in Grade } 2 \text { or } 3 \text {; (b) at the } \\
\text { end of primary education; and (c) at the end of lower secondary education }\end{array}$ & $\mathrm{X}$ & \\
\hline 4.1 .3 & Gross intake ratio to the last grade (primary education, lower secondary education) & $\mathrm{X}$ & \\
\hline 4.1 .4 & Completion rate (primary education, lower secondary education, upper secondary education) & $X$ & \\
\hline 4.1 .5 & Out-of-school rate (primary education, lower secondary education, upper secondary education) & $\mathrm{X}$ & \\
\hline 4.1 .6 & Percentage of children over age for grade (primary education, lower secondary education) & $X$ & \\
\hline 4.1 .7 & $\begin{array}{l}\text { Number of years of (a) free and (b) compulsory primary and secondary education guaranteed in } \\
\text { legal frameworks }\end{array}$ & $\mathrm{X}$ & \\
\hline
\end{tabular}

Target 4.2 By 2030, ensure that all girls and boys have access to quality early childhood development, care and pre-primary education so that they are ready for primary education

\begin{tabular}{|c|c|c|c|}
\hline 4.2 .1 & $\begin{array}{l}\text { Proportion of children under } 5 \text { years of age who are developmentally on track in health, } \\
\text { learning and psychosocial well being, by sex }\end{array}$ & $\mathrm{X}$ & $\mathrm{X}$ \\
\hline 4.2 .2 & Participation rate in organized learning (one year before the official primary entry age), by sex & $X$ & \\
\hline 4.2 .3 & $\begin{array}{l}\text { Percentage of children under } 5 \text { years experiencing positive and stimulating home learning } \\
\text { environments }\end{array}$ & & $x$ \\
\hline 4.2 .4 & $\begin{array}{l}\text { Gross early childhood education enrolment ratio in (a) pre-primary education and (b) early } \\
\text { childhood educational development }\end{array}$ & $\mathrm{X}$ & \\
\hline 4.2 .5 & $\begin{array}{l}\text { Number of years of (a) free and (b) compulsory pre-primary education guaranteed in legal } \\
\text { frameworks }\end{array}$ & $\mathrm{X}$ & \\
\hline \multicolumn{4}{|c|}{$\begin{array}{l}\text { Target } 4.3 \text { By 2030, ensure equal access for all women and men to affordable quality technical, vocational and tertiary education, } \\
\text { including university }\end{array}$} \\
\hline 4.3.1 & $\begin{array}{l}\text { Participation rate of youth and adults in formal and non-formal education and training in the } \\
\text { previous } 12 \text { months, by sex }\end{array}$ & $\mathrm{X}$ & $\mathrm{X}$ \\
\hline 4.3 .2 & Gross enrolment ratio for tertiary education by sex & $X$ & \\
\hline 4.3.3 & Participation rate in technical vocational programmes ( 15 to 24 year olds) by sex & $X$ & \\
\hline
\end{tabular}


Target 4.4 By 2030, substantially increase the number of youth and adults who have relevant skills, including technical and vocational skills, for employment, decent jobs and entrepreneurship

\begin{tabular}{|c|l|c|c|}
\hline 4.4 .1 & $\begin{array}{l}\text { Proportion of youth and adults with information and communications technology (ICT) skills, by } \\
\text { type of skill }\end{array}$ & $\mathrm{X}$ & $\mathrm{X}$ \\
\hline 4.4 .2 & $\begin{array}{l}\text { Percentage of youth/adults who have achieved at least a minimum level of proficiency in digital } \\
\text { literacy skills }\end{array}$ & $\mathrm{X}$ \\
\hline 4.4 .3 & $\begin{array}{l}\text { Youth/adult educational attainment rates by age group, economic activity status, levels of } \\
\text { education and programme orientation }\end{array}$ & $\mathrm{X}$ (to simplify) \\
\hline
\end{tabular}

Target 4.5 By 2030, eliminate gender disparities in education and ensure equal access to all levels of education and vocational training for the vulnerable, including persons with disabilities, indigenous peoples and children in vulnerable situations

\begin{tabular}{|c|c|c|c|}
\hline 4.5 .1 & $\begin{array}{l}\text { Parity indices (female/male, rural/urban, bottom/top wealth quintile and others such as } \\
\text { disability status, indigenous peoples and conflict affected, as data become available) for all } \\
\text { education indicators on this list that can be disaggregated }\end{array}$ & $\mathrm{X}$ & \\
\hline 4.5 .2 & $\begin{array}{l}\text { Percentage of students in primary education whose first or home language is the language of } \\
\text { instruction }\end{array}$ & & $\mathrm{X}$ \\
\hline 4.5 .3 & $\begin{array}{l}\text { Extent to which explicit formula based policies reallocate education resources to disadvantaged } \\
\text { populations }\end{array}$ & & $x$ \\
\hline 4.5 .4 & Education expenditure per student by level of education and source of funding & $\mathrm{X}$ & \\
\hline 4.5 .5 & Percentage of total aid to education allocated to least developed countries & $\mathrm{X}$ & \\
\hline \multicolumn{4}{|c|}{ Target 4.6 By 2030, ensure that all youth and aa substantial proportion of adults, both men and women, achieve literacy and numeracy } \\
\hline 4.6.1 & $\begin{array}{l}\text { Proportion of population in a given age group achieving at least a fixed level of proficiency in } \\
\text { functional (a) literacy and (b) numeracy skills, by sex }\end{array}$ & $\mathrm{X}$ & $x$ \\
\hline 4.6 .2 & Youth/adult literacy rate & $\mathrm{X}$ & \\
\hline 4.6 .3 & Participation rate of illiterate youth/adults in literacy programmes & & $\mathrm{x}$ \\
\hline \multicolumn{4}{|c|}{$\begin{array}{l}\text { Target 4.7 By 2030, ensure all learners acquire knowledge and skills needed to promote sustainable development, including among } \\
\text { others through education for sustainable development and sustainable lifestyles, human rights, gender equality, promotion of } \\
\text { a culture of peace and non-violence, global citizenship, and appreciation of cultural diversity and of culture's contribution to } \\
\text { sustainable development }\end{array}$} \\
\hline 4.7 .1 & $\begin{array}{l}\text { Extent to which (i) global citizenship education and (ii) education for sustainable development, } \\
\text { including gender equality and human rights, are mainstreamed at all levels in: (a) national } \\
\text { education policies, (b) curricula, (c) teacher education and (d) student assessment }\end{array}$ & $\mathrm{X}$ & $\mathrm{X}$ \\
\hline 4.7 .2 & Percentage of schools that provide life skills based HIV and sexuality education & & $\mathrm{x}$ \\
\hline 4.7 .3 & $\begin{array}{l}\text { Extent to which the framework on the World Programme on Human Rights Education is } \\
\text { implemented nationally (as per the UNGA Resolution 59/113) }\end{array}$ & & $\mathrm{x}$ \\
\hline
\end{tabular}




\begin{tabular}{|c|c|c|c|}
\hline \multirow{2}{*}{\multicolumn{2}{|c|}{ SDG 4 targets }} & \multicolumn{2}{|c|}{ Indicator status } \\
\hline & & \multirow{2}{*}{$\begin{array}{l}\text { Indicators for } \\
\text { reporting in } 2017\end{array}$} & \multirow{2}{*}{$\begin{array}{c}\text { Requires further } \\
\text { development }\end{array}$} \\
\hline 4.7.4 & $\begin{array}{l}\text { Percentage of students by age group (or education level) showing adequate understanding of } \\
\text { issues relating to global citizenship and sustainability }\end{array}$ & & \\
\hline 4.7.5 & $\begin{array}{l}\text { Percentage of } 15 \text { year old students showing proficiency in knowledge of environmental science } \\
\text { and geoscience }\end{array}$ & & $\mathrm{x}$ \\
\hline \multicolumn{4}{|c|}{$\begin{array}{l}\text { Target 4.a Build and upgrade education facilities that are child, disability and gender sensitive and provide safe, non-violent, inclusive } \\
\text { and effective learning environments for all }\end{array}$} \\
\hline 4.a.1 & $\begin{array}{l}\text { Proportion of schools with access to: (a) electricity; (b) Internet for pedagogical purposes; (c) } \\
\text { computers for pedagogical purposes; (d) adapted infrastructure and materials for students } \\
\text { with disabilities; (e) basic drinking water; (f) single sex basic sanitation facilities; and (g) basic } \\
\text { handwashing facilities (as per the WASH indicator definitions) }\end{array}$ & $x$ & $X$ for $(d)$ \\
\hline 4.a.2 & $\begin{array}{l}\text { Percentage of students experiencing bullying, corporal punishment, harassment, violence, } \\
\text { sexual discrimination and abuse }\end{array}$ & & $\mathrm{x}$ \\
\hline 4.a.3 & Number of attacks on students, personnel and institutions & & $x$ \\
\hline \multicolumn{4}{|c|}{$\begin{array}{l}\text { Target 4.b By 2020, substantially expand globally the number of scholarships available to developing countries, in particular least } \\
\text { developed countries, small island developing States and African countries, for enrolment in higher education, including } \\
\text { vocational training, information and communications technology, technical, engineering and scientific programmes in } \\
\text { developed countries and other developing countries }\end{array}$} \\
\hline 4.b.1 & Volume of official development assistance flows for scholarships by sector and type of study & $\mathrm{x}$ & \\
\hline 4.b.2 & Number of higher education scholarships awarded, by beneficiary country & & $\mathrm{x}$ \\
\hline \multicolumn{4}{|c|}{$\begin{array}{l}\text { Target 4.c By 2030, substantially increase the supply of qualified teachers, including through international cooperation for teacher } \\
\text { training in developing countries, especially least developed countries and small island developing States }\end{array}$} \\
\hline 4.c.1 & $\begin{array}{l}\text { Proportion of teachers in: (a) pre-primary education; (b) primary education; (c) lower secondary } \\
\text { education; and (d) upper secondary education who have received at least the minimum } \\
\text { organized teacher training (e.g., pedagogical training) pre-service or in-service required for } \\
\text { teaching at the relevant level in a given country, by sex }\end{array}$ & $x$ & \\
\hline 4.c. 2 & Pupil-trained teacher ratio by education level & $x$ & \\
\hline 4.c.3 & $\begin{array}{l}\text { Proportion of teachers qualified according to national standards by education level and type of } \\
\text { institution }\end{array}$ & $x$ & \\
\hline 4.c. 4 & Pupil-qualified teacher ratio by education level & $x$ & \\
\hline 4.c.5 & $\begin{array}{l}\text { Average teacher salary relative to other professions requiring a comparable level of } \\
\text { qualification }\end{array}$ & & $\mathrm{x}$ \\
\hline 4.c. 6 & Teacher attrition rate by education level & $x$ & \\
\hline 4.c.7 & Percentage of teachers who received in-service training in the last 12 months by type of training & & $\mathrm{x}$ \\
\hline
\end{tabular}

Note: Orange boxes are global indicators; blue boxes are thematic indicators. For information on definitions, methodology, interpretation and limitations for each indicator, please refer to UIS, 2017d.

Source: TCG, 2017. 


\section{Tier 1}

The indicator is conceptually clear and has an internationally-established methodology and standards. In addition, data are produced regularly by countries for at least $50 \%$ of countries and of the population in every region where the indicator is relevant.
4.2 .2
4.b. 1

\section{Tier 2}

The indicator is conceptually clear, has an internationally-established methodology and standards, but data are not regularly produced by countries.
4.1.1 (b) and (c)
4.3.1
4.4.1
4.6.1
4.c. 1

\section{Tier 3}

No internationally-established methodology or standards are yet available for the indicator, but methodology/standards are being (or will be) developed or tested.
4.1.1 (a)
4.2.1
4.7.1

\section{Mixed tiers}

4.a.1 Tier $1 / 2 / 3$ depending on the component

4.5.1 Tier 1/2/3 depending on the underlying indicator

Note: Tier classification from 20 April 2017 but includes the re-classification of 4.c.1 at the Sixth Meeting of the IAEG-SDGs ("Agenda Items 4.1. Tier reclassification based on data availability assessment", 11-14 November 2017, Manama, Kingdom of Bahrain.

Source: UNDESA, 2016. 
global indicator framework in 2019 and 2024 in preparation for the 2020 and 2025 UNSC review sessions. Substantive changes are only considered during these reviews. The members of the IAEG-SDGs determine the scope of the major reviews and will develop proposals to add, delete or modify selected indicators. They will consult widely on proposed changes through a series of open consultations with observer countries, regional and international organizations, civil society and other stakeholders. Additions may occur where the existing global indicators do not adequately cover the full intention of a given target or where existing global indicators are still not available at the time of the major review. Deletions of indicators could be considered when suitable methodologies cannot be developed on a global scale for a Tier 3 indicator or where existing indicators are not sufficiently powerful to measure progress. Modifications may be required for the purposes of clarification, simplification or where greater definition or discrimination is needed.

It is expected that the majority of the SDG 4 indicators in the current global framework will be retained. During 2016, the IAEG-SDGs expressed interest in considering additional global indicators for certain targets. Among these are out-ofschool rates, completion rates and the number of years of free education - all of which are thematic indicators - for Target 4.1. The IAEG-SDGs would also like to expand Indicator 4.b.1 on expenditure on scholarships for study abroad to include privately funded scholarships. Given the broad range of scholarship providers, these data are not collected systematically or comprehensively to date and cannot be reliably aggregated.

\subsubsection{The thematic indicator framework}

The development of a thematic indicator framework for SDG 4 results from the work that began with the UIS chaired process of developing education indicators for the Education 2030 Framework for Action. In March 2014, UNESCO established the Technical Advisory
Group on Post-2015 Education Indicators (TAG) whose mandate included the selection of a set of indicators to monitor SDG 4, ultimately included as a draft in the Education 2030 Framework for Action. TAG's selection of 43 indicators - 11 global indicators and 32 thematic indicators - was based on five criteria, namely, relevance, alignment with the concepts in the target, feasibility for regular data collection across countries, ease of communication to a global audience and interpretability (UIS, 2017e; UNESCO, 2015).

The Education 2030 Framework for Action mandated that the UIS work with partners to lead in data collection, indicator development and strengthening of national data systems. In 2016, the UIS convened the Technical Cooperation Group (TCG) on the SDG 4-Education 2030 Indicators to lead the methodological development and implementation of the thematic indicator framework, designed to monitor comprehensively the global education targets. The TCG is composed of regionally-representative experts from 28 Member States (the same regional representation as the IAEG-SDGs and the United Kingdom, a former member), the GEM Report team, the OECD, UNESCO, UNICEF, the World Bank and civil society organizations, as well as observers from regional commissions and agencies and countries in the Education 2030 Steering Committee. The UIS hosts the Secretariat and co-chairs the TCG with the UNESCO Division for Education 2030 Support.

In October 2016, the TCG approved a set of 29 indicators (11 global and 18 thematic) available for reporting in 2017 based on the original list of 43 proposed SDG 4 indicators (see Table 1). The Global Education 2030 Steering Committee - a coordination mechanism hosted by UNESCO to support Member States and partners - endorsed the 29 indicators in their December 2016 meeting and hence provided important political support for adoption by countries. While the Steering Committee has a continuing coordinating role, it does not revisit the technical discussion around indicator selection.

\footnotetext{
${ }^{7}$ Refinements can include the following types of changes: "specifying or correcting unit of measurement; simple clarification of terms used in the indicator; spelling and other obvious errors; or 'splitting' indicators into their components in multiple component indicators. A refinement can also be a minor change in an indicator or indicator list that will, in a simple way, solve a problem that is spotted when the collection of data has begun" (IAEG-SDGs, 2016, p. 2).
} 
In 2016, the UIS also created the Global Alliance to Monitor Learning (GAML) to advise on the methodological development of the learning outcomes related SDG 4 indicators (global and thematic). GAML is composed of a broad array of experts and decisionmakers involved in national and cross national learning assessment initiatives, as well as donors and civil society organizations advocating for education. GAML operates through dedicated task forces for each of the learning outcomes related targets (4.1, 4.2. 4.4. 4.6 and 4.7) as well as a cross cutting task force to develop a Data Quality Assessment Framework (DQAF) for learning assessments. GAML's experts also lead the development of standards and good practices in learning assessments.

When the TCG approved the 29 indicators for reporting in 2017, it also identified 22 indicators which required further methodological development. Of these, 14 are the remaining thematic indicators of the original 43 indicators and another 8 are global indicators included in the list of the 29 for reporting in 2017 (see Table 1). The TCG established the Working Group on Indicator Development (WG ID) - composed of eight to ten TCG participants - with the mandate of finalising the methodologies for 15 of the 22 indicators. ${ }^{8}$ GAML will develop methodologies for the remaining seven indicators, which concern learning outcomes. As of early 2017, the WG ID and GAML task forces have been reviewing existing methodologies and data sources for their respective sets of indicators and consulting external experts as appropriate. They aim to make recommendations to the TCG on the most appropriate methodologies for the 22 indicators, thereby completing the development work for all 43 indicators by the end of 2018. Once the TCG approves the methodologies, the remaining 22 indicators will be ready for future reporting. In addition, the UIS will submit proposals for the annual IAEGSDGs review to change the tier classification of the relevant global indicators. The TCG and the GAML's work will also include advice from the UIS and its partner agencies for the major IAEGSDGs reviews in 2019 and 2024.

\subsection{The challenge of producing the required data for the indicators}

The statistical capacity of most countries is being put to the test by the breadth, depth and ambition of the global education goals. The emphasis on equity and quality of education by the 2030 Agenda for Sustainable Development and the more comprehensive nature of the SDGs relative to the MDGs require more data than before and from a wider range of sources: administrative data, financial data, census, household surveys as well as national, regional and international learning assessments. Data requirements also include increased cooperation among different national ministries, agencies and other data custodians to cover the breadth of the SDG 4 from early childhood care and education to higher education and lifelong learning. Inputs from other sectors, such as health, women's affairs and labour, are required to produce data for the education related indicators in other SDGs (UNESCO, 2016).

A recent assessment of national statistical capacity with regard to SDG 4 data collection underscores the challenge ahead for the production of quality indicators. In 2016, the UIS conducted assessments of data availability at the country level to monitor SDG 4. Staff responsible for education statistics in 121 countries in the Arab States, Asia and the Pacific, Latin America and the Caribbean, and sub Saharan Africa identified whether they already regularly produce the data required for the 43 global and thematic indicators. Fewer than one-half (47\%) had sufficient data for the 11 global indicators, but nearly two thirds $(63 \%)$ reported having the data needed to calculate the remaining 32 thematic indicators (not including the global indicators).

\footnotetext{
${ }^{8}$ The TCG's Working Groups have about six to ten self-nominated members each, usually including at least three TCG member countries, two civil society or partner organizations, and one UIS staff acting as Secretariat. Observers of the TCG can be invited to join the working groups.
} 
When the data are available, the quality and extent of data collection do not always meet SDG 4 expectations. Disaggregating data by measures of wealth and disability status, for example, was possible in only $14 \%$ and $19 \%$ of countries, respectively. Some concepts in SDG 4 are more likely to already be collected, such as participation and completion data which are available in $85 \%$ of the countries. Data on knowledge, skills, learning and school readiness, however, are available in only $43 \%$ of responding countries (UIS, 2016).
Country coverage in the UIS database is lower than the 2016 assessment suggested.

Figure 2 shows the availability of global and thematic indicators across all countries reporting in the UIS database in 2017: 10 of the 43 indicators were unavailable in all countries, while 8 global indicators and 11 thematic indicators are reported in $50 \%$ or fewer countries. Only one global indicator and six other thematic indicators have more than $75 \%$ coverage. Countries are struggling to report and, in many cases, collect the data

Figure 2. SDG 4 global and thematic indicator availability in the UIS database, June 2017

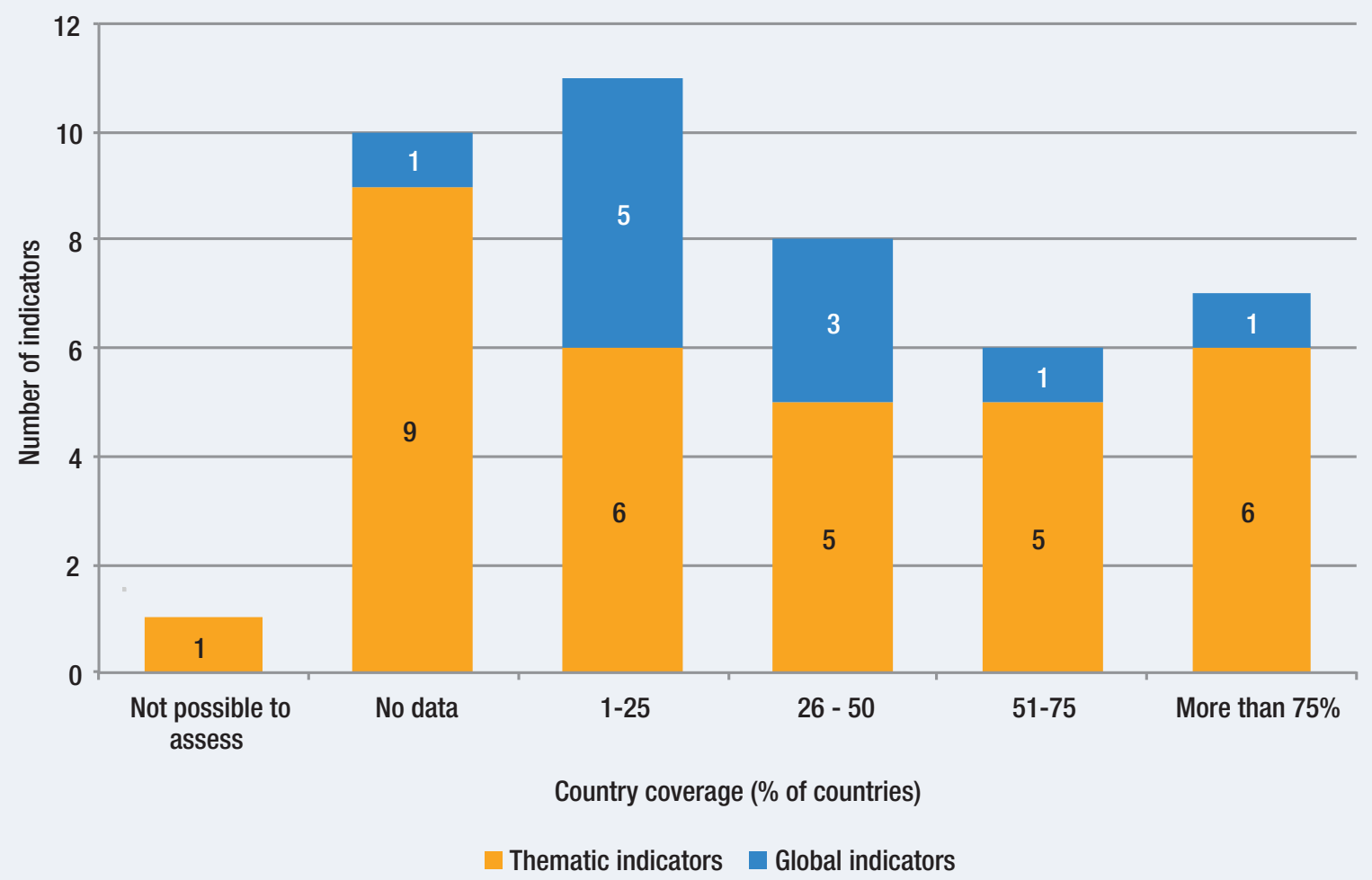

Source: Based on UNESCO Institute for Statistics, 2017c. 
needed for calculating key indicators for the follow up and review of SDG 4 (UIS, 2017c).

The 2030 Agenda and the Education 2030 Framework for Action explicitly call upon international organizations and other stakeholders with technical expertise to support capacity building in data collection efforts required for the SDGs. The TCG has taken the lead in helping countries increase their technical capacity to collect and report data for the SDG 4 indicators. In early 2017, it established the Working Group on Statistical Capacity Building (WG SCB) and the Working Group on Data Reporting, Validation and Dissemination (WG DRVD) in addition to the aforementioned WG ID. The working groups report back to the full TCG, which makes decisions based on their recommendations.

The WG SCB is developing a framework of capacity building tools and guidelines to assist countries to assess their specific needs for capacity development and to identify sources of support. The framework will bring together existing tools and guidelines from a variety of sources. The working group will also identify gaps in the framework and make recommendations for the development of additional tools and guidelines.

The WG DRVD is mapping the flow of data from countries to international organizations and then to the UNSD for inclusion in the SDG Indicators Global Database. The group will identify the schedule for each data collection exercise and the organizations responsible. It will describe the quality assurance processes and feedback loops to countries for validation of final results. The group will make recommendations for a protocol between countries and organizations to ensure the efficient and transparent flow of data and agreement on results to be published.

The 2030 Agenda and the Education 2030

Framework for Action also call for the mobilisation of international public finance notably oversees development assistance - to help implement the SDGs and complement domestic resources, especially in the poorest countries. The UIS has estimated that meeting the data needs of the education agenda would cost around US $\$ 2.2$ billion over ten years; $43 \%$ of these total costs involve the use of regular sample-based learning assessments in early and late primary grades (UIS, 2017i). The private sector is encouraged to contribute to education coffers, while maintaining the respect of accountability, transparency and equity and in partnership with the public sector. The UIS has specifically recommended that the private sector mobilise in kind contributions to support the improvement of data collection and production (UIS, 2017i).

Expanding a country's capacity to collect and report data is a necessary first step to producing cross national comparable indicators. But it is not sufficient on its own. The other indispensable step is assessing the quality of the data being produced relative to international quality standards. This is the topic of Section 2. Accordingly, building the statistical foundations to properly monitor progress towards the education goal and targets must be focused on the production of quality data.

The term quality is interpreted in a broad sense, encompassing all aspects of how well statistical processes and their outputs fulfil the expectations of users and stakeholders (see Box 2). Over the past 20 years, statistical agencies have arrived at a consensus that the concept of quality of statistical information is multi dimensional and that there is no single measure of data quality. Particular efforts will be required to ensure that quality is an objective across all data production phases (development, collection, processing, validation and dissemination).

Enabling these efforts in a systematic way across national and international data production mechanisms and for a variety of data sources is the object of several UIS efforts. Section 2 discusses recent initiatives to promote a standardised level of quality across all SDG 4 data collection efforts. Section 3, which follows, considers specific capacity development strategies to support national education statistical systems. 
The concepts listed below are often used to collectively evaluate the level of quality observed across the processes of data collection and dissemination. Not all dimensions have to be of the highest standard to reach the level of quality data, but it is essential to use a selection of these characteristics as benchmarks to validate the quality of data outputs.

Relevance. The relevance of a statistical output is the degree to which the data serve to address the purposes for which they are sought by users.

Accuracy. The accuracy of a statistical output is the degree to which the data correctly estimate or describe the quantities or characteristics they are designed to measure. Accuracy refers to the closeness between the values provided in the product and the (unknown) true values.

Reliability. It is the closeness of the initially released values of a statistical output to the values that are subsequently released for the same reference period.

Coherence. The coherence of a statistical output reflects the degree to which it is logically connected and mutually consistent with other statistical outputs. Coherence implies that the same term should not be used without explanation for different concepts.

Timeliness. The timeliness of a statistical output is the length of time between its availability and the event or phenomenon it describes. Timeliness is assessed in terms of a time scale that depends upon the period for which the data are of value, i.e. are sufficiently timely to be acted upon.

Punctuality. The punctuality of a statistical output implies the existence of and adherence to an output dissemination schedule. An output is punctual if it is disseminated in accordance with the schedule.

Accessibility. The accessibility of a statistical output reflects how readily the data can be discovered, located and accessed from within data holdings. It includes the suitability of the formats in which the data are available, the media of dissemination, the availability of metadata and user support services, and, in the event that there is a charge, the affordability of the data to users.

Interpretability. The interpretability or clarity of a statistical output reflects the ease with which users can understand and properly use the data. The degree of interpretability is largely determined by the adequacy of the metadata that accompany the data, including definitions of concepts, target populations, indicators and other terminology describing the output and its limitations.

Objectivity. Statistical methods and outputs are determined by statistical considerations and not by pressure from providers, users or other stakeholders.

Impartiality. Commentaries and press releases are objective and non-partisan.

Transparency. Users are informed about sources and methods and about changes to these that might affect the outputs. The limitations of the outputs, and of the processes by which they are produced, are acknowledged.

Credibility: It refers to the confidence that users have in the products based primarily on their image of the producer and its statistical outputs, as well as in their trust in the objectivity and impartiality of the methods used. 


\section{Producing quality statistics to monitor progress towards SDG 4}

As custodian of the majority of international education statistics for the SDG 4-Education 2030 Agenda, the UIS has a vision to produce quality data to assess the progress of the international education goals. Reflecting on the ambitious education agenda, the UIS and the international statistical community have identified data gaps and other methodological challenges facing the development of global and thematic indicators for education. The main challenge, however, is establishing and strengthening the production of education data of the required quality in a systematic and sustainable manner. This lays the foundation for new methodological approaches and data collection efforts.

In 2017, the UIS issued an urgent call for a data revolution in education to address those challenges hindering the production of quality data to monitor SDG 4. Based on decades of experience working to improve national education statistical systems and collecting international education data, the UIS recognises that the ambitious nature of SDG 4 requires new methodological approaches to assess and improve the production of quality education data at both the national and international levels. The UIS also understands the need to consider the strategic objectives of quality data production from both the national and international perspectives. Quality requirements at the national level reflect the use of data to monitor national practices and policies and formulate evidence based responses to policy challenges. Data quality needs at the international level are based on the reliability, timeliness and comparability of cross-country education data.

As such, establishing and strengthening data quality systemically across national and international levels poses significant and distinct challenges. Yet, at each level, data quality reflects the quality of the process that produced the data and the robustness of the SDG 4 global monitoring framework relies on the quality of data produced at the national level. This section begins by describing the UIS vision for quality data and the need for a data revolution in education. It then describes the actions taken by the UIS to improve data quality standards to monitor the SDG 4-Education 2030 Agenda at the national and international levels.

\subsection{A data revolution in education}

The UIS has called for a data revolution in education to establish an effective system for monitoring progress towards the SDGs that would meet the standards needed to produce quality data (see Section 1.3). The main objectives of the data revolution in education respond to the need to fill multiple "gaps in terms of norms and standards, data availability, methods to measure key indicators, and coordination among different stakeholders that affect the entire chain of education data production and use" (UIS, 2017i, p. 48).

The UIS model of a data revolution requires strengthening national statistical systems which are the foundation of the monitoring system and building international support mechanisms for an efficient production of cross national comparable indicators. ${ }^{9}$ The international community, which includes public and private actors, provides critical support for achieving the global compact for monitoring SDG 4. Each of these core components of the data revolution is composed of three broad target areas at the country and international levels. The three pillars, around which the Fundamental Principles of Official Statistics are organized, include: enabling environments, data production and data dissemination (see Figure 3).

\footnotetext{
${ }^{9}$ For more information on the underlying challenges in education data processes, see UIS, 2017i.
} 
- Enabling environments: Investments in technical and financial resources to meet challenges faced by national statistical organizations; investments in technology and trained personnel; governance of education agencies and national statistical offices.
- Data production: Improvement of data collection according to international norms and standards; government prioritisation of data collection on a regular basis; harmonisation of standards for collecting data in new areas (e.g. learning outcomes); expansion of other reliable data sources.

\section{Figure 3. Components of the data revolution in education}

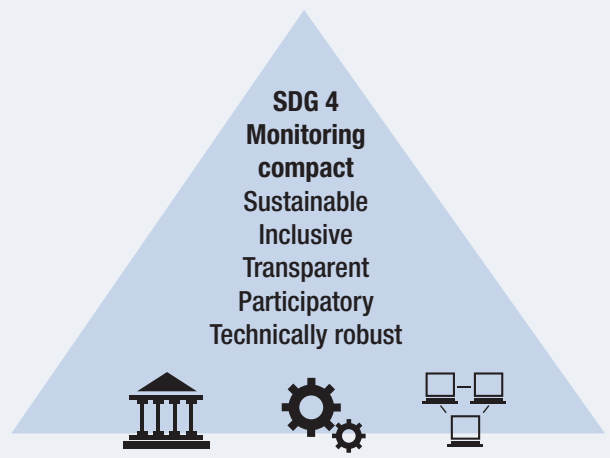

International support as enabling factor

Enabling environment

Roles and responsibilities defined accurately.

Participatory approach for methodological developments.

Methodologies sensitive to inclusion of all populations.

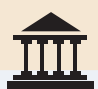

Sound data production Transparency.

Robustness.

Validation with countries.

Inclusiveness of all possible data sources.

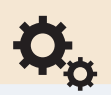

Data use and dissemination Reduce inter-agency costs of data exchanges.

Transfer knowledge and ownership to countries.

Peer-learning processes.

\section{Country statistical systems as the foundation}

\section{Enabling environment}

National strategies for education statistics.

Align:

- Data to national priorities.

- Political commitment and resources to data needs.

Inter- and intra-ministry collaboration and stakeholder engagement

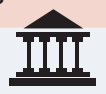

Sound data production

National Education Statistical

System: cornerstone of national and global monitoring tools.

Integrate data sources to cover all SDG 4 targets and improve quality control.

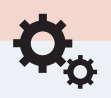

Data use and dissemination Increase data literacy and use of education statistics for policymaking. Serviceability for different stakeholders, including teachers and families. Dissemination of metadata. 
- Data use and dissemination: Strengthening mechanisms for data dissemination and use; use of technology to broaden impact of data and information.

The discussion of the current role and activities of the UIS in improving the quality of education data at the national and international levels is the subject of the subsequent parts of Section 2. As a foundation for this work, the UIS has developed the Code of Practice (CoP) for education statistics, which is implemented through the Education Data Quality Assessment Framework (Ed-DQAF). The CoP is a set of statistical principles measured by relevant indicators - which define the elements that are necessary for producing quality data in the institutional environment, as well as statistical processes and education statistical outputs. Applied at the national level, the Ed-DQAF integrates the CoP into a series of activities and processes against which a country can measure its data production system. Although the CoP was produced by the UIS in 2017 as a stand alone document, in practice, it was already embedded in the methodology of the Ed-DQAF that has been implemented by the UIS since 2005.

It is important also to acknowledge the role of international organizations, global financial partners, education advocates and other groups, which are actively supporting national and regional efforts to produce quality statistics. Within this work strategy, similar codes of practices to improve the production of quality statistics have been adopted by international organizations, global financial partners and other regional groups.

A leading example is the European Statistics Code of Practice, first adopted by the European Statistical System Committee in 2005. The 2011 revision consists of a set of 15 key principles which guide the production and dissemination of official European statistics and provide a standard institutional environment within which national and European statistical authorities (Eurostat and the European Statistical System) operate. The Quality Assurance Framework (QAF) of the European Statistical System, published in 2011, provides guidance on how to implement the European Statistics Code of Practice. It contains recommendations of activities, methods and tools to improve the implementation of indicators by examining the institutional environment, statistical processes and statistical outputs (ESS, 2015; Eurostat, 2011).

The European CoP and QAF have served as models for regional organizations developing their own tools, as in Latin America and the Caribbean (see Box 3). By developing regional assessment frameworks, regional networks and organizations set a regional standard for improving statistical systems and their enabling environments. The improvement of data production thereafter becomes a collective objective within a group of peers.

In recent years, the UN statistical community has also developed and adopted two quality assurance products: the National Quality Assurance Framework (NQAF) for use by countries and the Statistics Quality Assurance Frameworks (UN SQAF) for use by UN agencies producing statistics (see Box 4).

At the national level, there have been several experiences to implement data quality frameworks in developed countries such as Canada, France, the Netherlands and the United Kingdom. This approach has also been adopted by certain developing countries: the case of Colombia's national statistical office, Departamento Administrativo Nacional de Estadística (DANE), provides an effective example of the production of a national data quality framework to improve national statistical systems (see Box 5). ${ }^{10}$

\footnotetext{
${ }^{10} \mathrm{~A}$ comprehensive list of data quality references can be found on UNSD website at https://unstats.un.org/unsd/dnss/QualityNQAF/nqaf.aspx.
} 


\section{Box 3. A code of good practice in statistics for Latin America and the Caribbean}

In 2007, several Latin American and Caribbean countries in the region proposed to the Statistical Conference of the Americas of the Economic Commission for Latin America and the Caribbean (SCA-ECLAC) to take note of the European Statistics Code of Practice and discuss the possibility of adapting it to the reality of each country. The SCA-ECLAC requested that Eurostat and ECLAC prepare a programme of action for carrying out this task.

By November 2011, the code of good practice in statistics for Latin America and the Caribbean was approved by the SCAECLAC. The code is a technical and regulatory instrument, structured by principles and best practices, which aims to contribute to the improvement of national statistical production in the region. Its principles are fundamental rules and ideas that govern the thinking and practice of statistical activity. Best statistical practices are seen as replicable actions based on proven experience with the best results, contributing to the improvement of national statistical activity. The code lists 17 principles and 84 criteria for compliance, grouped into three sections: institutional environment and coordination, statistical processes and statistical outputs.

As a technical document, the code contains practical rules for ensuring the independence of the national statistical institutes and the coordination of statistical production at the national level. Not only does it serve as a guide for improving the quality of statistics produced in the region, but it also seeks to coordinate statistical activity, improve the quality of official statistics and build trust in users by encouraging the application of best international methods and practices in statistical production and dissemination.

Sources: ECLAC, 2011a, 2011b.

\section{Box 4. The United Nations National Quality Assurance Framework (NQAF) and the United} Nations Statistical Quality Assurance Framework (UN SQAF)

In 2012, the UNSD produced a generic National Quality Assurance Framework (NQAF), together with a template and guidelines, to assist countries in developing their own statistics quality assurance frameworks. The UN's NQAF has been endorsed by the UNSC and is being progressively implemented by countries. The template is a generic structure within which countries can formulate and operationalise their own national quality frameworks or further enhance existing ones. The guidelines support the template by providing lists of tools and references specific to Section 3 of the template (quality assurance guidelines) and Section 4 (quality assessment). The guidelines include a detailed map showing links with several existing QAFs as well as links to the online NQAF glossary.
In 2016, the Committee of the Chief Statisticians of the United Nations System (CCS-UNS) developed the United Nations Statistical Quality Assurance Framework (UN SQAF). Based on existing sets of principles for statistical activities for international organizations - namely the 2014 Principles Governing International Statistical Activities - the UN SQAF aims to develop a common understanding of quality dimensions and quality assurance for statistics among UN agencies, which can be adapted to the specific circumstances of an individual agency. The UN SQAF also provides a basis for the review and updating of existing SQAFs by UN agencies, including guidelines for the coordination and promotion of better quality data across the UN statistical system. 


\section{Box 5. National data quality frameworks: The case of Colombia}

One of the key foundational instruments to strength the national statistical system in Colombia is the national quality assurance framework (Aseguramiento de la calidad de la información estadística), which has been in place since 2006.

During the 1990s, Colombia sought to improve the quality of national statistics through several early initiatives, including the development of a dedicated department within the national statistical office Departamento Administrativo Nacional de Estadística (DANE) - to develop and establish methodologies and processes to evaluate data quality. DANE received information and support from international organizations (e.g. ECLAC, FAO) and researchers from various countries (e.g. Canada, Chile, France, Mexico) to explain the foundations for producing quality data and emphasise the need for data evaluation using a national quality assurance framework.

Sources: DANE, 2017; OECD, 2015.
In 2006, the national quality assurance framework was established by government decree within DANE. National statistical operations are regularly evaluated by an audit and certification process within the national quality assurance framework that involves four steps: outreach, data collection, evaluation and certification. Between 2007 and 2016, 255 quality evaluations were implemented and $81 \%$ of the statistical operations were certified. This certification process guarantees that official statistics emanating from various parts of the national and sub-national statistical system are produced under similar methodological standards.

An ambitious research agenda reviews the national framework every three years to improve the statistical quality of Colombian statistics. Most recently, the certification process was revised to align with the Fundamental Principles of Official Statistics adopted by the UN General Assembly in 2014, creating an institutional framework favouring credibility, reliability and transparency in the production of statistics.

\subsection{Producing education data at the national level according to quality standards}

\subsubsection{Defining and implementing the standards}

Since its creation, the UIS has been involved in a variety of activities to improve education data quality at the national level. In 2005, the UIS and the World Bank developed the Ed-DQAF, which consists of a scoring matrix to assess the quality of data routinely produced by countries and to formulate recommendations for improvements.
The model reference for this document was the generic data quality assessment framework produced by the International Monetary Fund (IMF) around six dimensions of data quality: pre-requisites of quality, assurances of integrity, methodological soundness, accuracy and reliability, serviceability and accessibility (IMF, 2012). The matrix is organized in a cascading structure that proceeds from general dimensions to more concrete and specific details:

- First-digit level: six quality dimensions based on the five proposed by the IMF's framework and adding the dimension " 0 " of "prerequisites of quality"; 
- Two-digit level: sub-dimensions of quality;

- Three-digit level: indicators; and

- Four-digit level: good practices for education statistics.

Practices describe quality features or requirements that may be considered in assessing the indicators. The essential part of the assessment consists in scoring each of these practices, on an ordinal scale from 1 (practice not observed) to 4 (practice observed). The assessment of the processes, followed by the entity responsible for the data source, is implemented by external evaluators in collaboration with the national team.

The production of the SDG 4 indicators brings the challenge of producing quality national education data onto a global scale requiring at the very least a systematic process. The data revolution thus sets the tone for leveraging various systems to produce quality data. During 2017, the UIS developed a plan in line with one of the main recommendations of the data revolution, which called for looking at countries' statistical systems as the foundation to implement that change and reaching national education statistics.

In this context, the Ed-DQAF is a nationallevel tool, which provides a comprehensive evaluation of the quality of education data. It becomes a central cornerstone to identifying weaknesses and strengths of the existing data production system within a process that should lead to the design of a national strategy to address the new monitoring challenges.

The Ed-DQAF assesses the production process, the management of data outputs and the characteristics of the enabling statistical environment or infrastructure, thereby covering all stages and aspects of data collection, processing and dissemination. Adapted for each data source, the framework gauges the quality of produced education data against current international standards and practices that establish expected quality levels. The assessment methodology relies on the assumption that national education statistics meet quality statistical standards when they are produced in a process that meets the standards and norms defined by the EdDQAF methodology. The ultimate objective of the data production process is sound statistical information about education to inform policy, research and decision making at both national and international level.

In May 2017, the UIS proposed a CoP specific to education statistics, composed of 12 principles of quality related to the institutional environment, statistical production processes and statistical outputs (see Box 6). Underpinning the development of the Ed-DQAF, each principle has a set of indicators serving as a reference for a thorough review of the implementation (see Annex 1).

The CoP for education statistics aims to ensure that the education statistics, which are mainly produced from administrative data, are not only relevant, timely and accurate but also comply with principles of professional independence, impartiality and objectivity. The target national audience for the CoP are the different stakeholders involved in the production of education statistics, most notably ministries of education and national statistical agencies.

It is beneficial to assess the implementation of the CoP through an external peer review process on a periodic basic. Members of the external review team should be independent of the implementing organizations and must be familiar with education, statistics and quality management issues. The scope of the review could be either the entire national education sector or a ministry or agency, or an education sub-sector. 


\section{Box 6. The 12 principles of the Code of Practice for education statistics}

Institutional environment: Institutional and organizational factors have a significant influence on the effectiveness and creditability of ministries of education that are developing, producing and disseminating education statistics. The relevant aspects are policy and the legal framework, adequacy of resources, quality awareness, professionalism, transparency and ethical standards.

- Principle 1: Policy and the legal framework. The legal and institutional environment governing education statistics has a significant influence on the effectiveness and credibility of a ministry of education to produce and disseminate education statistics.

- Principle 2: Adequacy of resources. The ministry of education ensures that resources are commensurate with the statistical programmes, personnel, facilities, equipment, technology, training and financing of their education management information systems.

- Principle 3: Quality awareness. Quality is a cornerstone of statistical work. Ministries of education systematically and regularly identify strengths and weaknesses to continuously improve the quality of both process and product.

- Principle 4: Professionalism. Statistical policies and practices are guided by professional principles.

- Principle 5: Transparency. Ministries of education develop, produce and disseminate education statistics in an objective and transparent manner in which all users are treated equitably.

- Principle 6: Ethical standards. Policies and practices are guided by ethical standards.
Statistical processes: International standards, guidelines and good practices are fully observed in the processes used by the ministries to organize, collect, process and disseminate official statistics. The credibility of the statistics is enhanced by a reputation for good management and efficiency. The relevant aspects are methodological soundness.

- Principle 7: Sound methodology. The methodological basis for the education statistics follows internationally-accepted standards, guidelines or good practices.

- Principle 8: Accuracy and reliability. Data sources and statistical techniques are sound and education statistical outputs sufficiently portray reality.

Education statistical outputs: The available statistics meet users' needs. Education statistics comply with international quality standards and serve the needs of international institutions, governments, research institutions, business concerns and the public generally. The important issues concern relevance, periodicity and timeliness, consistency and accessibility and clarity.

- Principle 9: Relevance. Education statistics meet the needs of users.

- Principle 10: Periodicity and timeliness. Education statistics are released following internationally-accepted periodicity and in a timely manner.

- Principle 11: Consistency. Released education statistics are consistent within a dataset and over time, and with other major datasets.

- Principle 12: Accessibility and clarity. Education statistics and metadata are easily available in a clear and understandable manner, and adequate user support is available. 
The Ed-DQAF serves as the tool to implement the principles of CoP, which are integrated into the Ed-DQAF as the third level of the structure with indicators as the fourth level. The DQAF methodology was created based on three principles governing the quality of education statistics at the national level and is aligned with the UN Fundamental Principles of Official Statistics adopted by the UN General Assembly (UNGA) in 2014 and with the UN's NQAF (see Box 4). These general principles are:

- Fitness for use. The quality of statistical information is understood in a broad sense, encompassing all aspects of how well statistical processes deliver outputs that fulfil users' expectations. Good quality outputs are statistics that are fit for purpose from the user's perspective, more specifically meaning that they are relevant, accurate, reliable, coherent, timely, accessible and interpretable. Good quality statistical production processes are processes that use sound methodology and systems, use internationally-agreed concepts, classifications and methods, and are cost effective.

- Effectiveness of Fundamental Principles of Official Statistics. The institutional environment guarantees the effectiveness of Fundamental Principles of Official Statistics and recognises the need for objectivity, impartiality, transparency and statistical coordination. Moreover, individual data collected by statistical units are to be strictly confidential and used exclusively for statistical purposes.

- Quality awareness. Long term and sustained support by senior management is crucial to the successful implementation of a quality assurance policy. Operational managers must give due consideration to monitoring the quality of the collection, processing, and dissemination of statistics and deal with quality considerations in planning the statistical programme. Every organization needs to have a quality management system in place to identify users' expectations and to ensure that all the statistical and supporting processes perform according to the requirements they are designed to meet (UN, 2014).

The Ed-DQAF structure is organized in a cascading structure, which proceeds from the more abstract to the more concrete across the four overlapping levels: dimensions, subdimensions, indicators and good practices. The top-most level is composed of three sections: the enabling environment, statistical processes and education statistical outputs. The second level is the quality dimension, two for each section. Each quality dimension is aligned with the third level, which corresponds to anywhere from one to three of the CoP quality principles. The links between the Ed-DQAF structure, the UIS CoP and the UN's NQAF are presented in Annex 2.

\subsubsection{Using data quality assessment frameworks with national education statistics}

The UIS has been implementing data quality assessment frameworks at two levels to improve national education statistics.

The Ed-DQAF was designed for use within the context of a National Education Statistical System (NESS), which is part of the broader national statistical system mandated to produce official statistics for policy and planning. NESS is at the centre of collecting, processing, disseminating and using data on education and thus, follows national and international sets of definitions, methodologies, classifications and tools. To monitor the education sector, NESS must effectively integrate different data sources, including administrative datasets (collected and stored under education management and information systems (EMIS)), household surveys, learning assessments and finance and expenditure datasets. However, many countries lack well established systems that integrate these different data sources (UIS, 2016).

In many countries regardless of their stage of development, the coordination of the fragmented 


\section{Figure 4. Structure of Ed-DQAF for administrative data}

The institutional environment guaranties the effectiveness of fundamental principles of official statistics.

Principles 1 to $3-9$ indicators Assurances of integrity. The principle of objectivity in the collection, processing and dissemination of statistics is firmly adhered to. Principles 4 to $6-11$ indicators

The methodological basis for the statistics follows internationally-accepted standards, guidelinesand good practices. Principle $7-4$ indicators

Source data and statistical techniques are sound and statistical outputs sufficiently portray reality. Principle $8-5$ indicators

Statistics are relevant and with adequate periodicity and timeliness, are consistent and follow a predictable revisions policy. Principles 9 to $11-9$ indicators

Data and metadata are easily available and assistance to users is adequate. Principle $12-3$ indicators

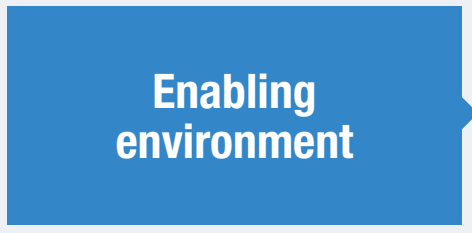

\section{Pre-requisite of quality}

Integrity
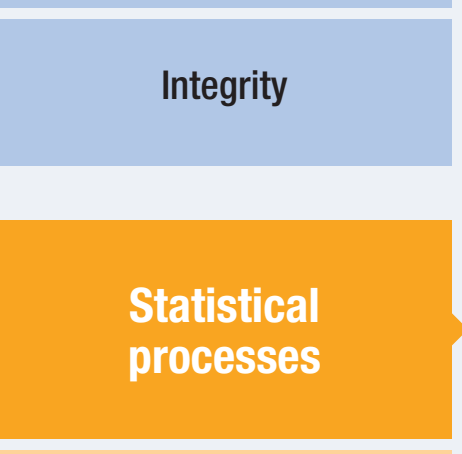

\section{Methodological soundness}

Accuracy and reliability

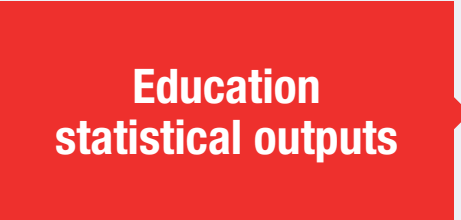

Serviceability

Accessibility
Institutional and organizational factors have a significant influence on the effectiveness and creditability of ministries of education that develop, produce and disseminate education statistics. These include policies and legal frameworks, adequate resources, quality control, professionalism, transparency and ethical standards.

International standards, guidelines and good practices are fully observed in the processes used by the ministries to organize, collect, process and disseminate official statistics. The credibility of the statistics is enhanced by a reputation of good management and efficiency. These include methodological soundness, accuracy and reliability.
Available statistics meet user needs. Education statistics comply with international quality standards and serve the needs of international institutions, governments, research institutions, business concerns and the public in general. The important issues concern relevance, periodicity and timeliness, consistency and accessibility and clarity. 
and parallel statistical systems in place is one of the biggest challenges in developing quality education data. The monitoring of education systems is the responsibility of multiple ministries, agencies and departments across various levels of government reflecting the structure of the education system. In many countries, the statistical function is highly decentralised, whereby statistics are produced independently in a number of organizational units without a substantial coordinating role and without a central sector-wide EMIS federating the various management information systems in ministries or agencies. Statistical monitoring activities also tend to follow the organization of education activities, organized and grouped along the main education subsectors: early childhood, primary, secondary general and vocational, post secondary nontertiary and tertiary.

To facilitate the quality assessment of statistical activities, statistical production activities run by data collecting entities can be viewed as separate autonomous statistical production processes, each of which:

- Is under the control of a single unit;

- Covers one or several education sub-sectors, or a specified topic (financing, learning assessment, teachers, etc.) or a range of education topics;

- Acquires data from a specific source or set of sources; and

- Produces a specific statistical product or set of related products.

Whatever the level of coordination, the common goal of the member organization of NESS should be that education statistics produced by NESS are harmonised in the sense that they use common concepts, classifications and definitions as much as possible and that the data produced by different organizations are mutually compatible. Coordination is made easier when members share the same understanding of quality issues and refer to a common set of principles and to a common quality assurance framework to organize their statistical activities.

As such, the UIS recommends that each organization producing data relevant for the education sector formally endorses the 12 quality principles as structured in the CoP for education statistics. In turn, they should present the CoP and direct units in charge of education statistics to implement the CoP and refer to the Ed-DQAF to monitor the quality of their statistical production. The Ed-DQAF used at the national level integrates a set of quality indicators for each principle in the CoP, which should be used when designing new activities, reorganizing existing processes and when monitoring or assessing processes.

The framework is intended to assure quality when designing or re designing a statistical process and when assessing the quality performance of a running statistical process. For both purposes, it is necessary to document the generic DQAF on the objectives of the process by specifying the methodological basis (Principle 7), the sources and techniques (Principle 8), user satisfaction (Principle 9) and the planned periodicity and timeliness (Principle 10). In addition, staff in charge of the assessment process require a manual, which includes general guidelines for each of the principles, and related to each indicator, more detail good practices for implementation, instructions, methods and procedures, and quality monitoring mechanisms.

Two types of assessments can be conducted using the documented framework: quality selfassessment and external quality assessment.

- A self-assessment of quality is conducted by the staff responsible for the statistical process, at least annually; its objectives are to help the staff responsible to develop an impression of the quality of their process and products, and hence to identify structural weaknesses and to propose quality improvements. 
- For external assessments, objectives are similar and mainly focused on the actual implementation of the quality guidelines in use. Unlike for self-assessments, members of the assessment team (or peers) are not involved in the running of the statistical process under review, but they must be familiar with quality assurance of the production of education or other statistics.

Both assessment exercises involve implementation and follow up with meetings with staff responsible for all aspects of processing, principal data users and key data providers. Participants can monitor actions taken in response to recommendations made during earlier assessments. The use of a check list derived from the good practices facilitates this assessment exercise; a scale can be used to evaluate the degree of conformity with each expected practice. Box 7 provides an example of measures used by the UIS when assessing national education statistics.

\section{Box 7. Checklists used during quality assessments: The example of Principle 8}

\section{Principle 8 Accuracy and reliability. Data sources and statistical techniques are sound and education statistical outputs sufficiently portray reality.}

Indicator 8.1: Available data sources provide an adequate basis to compile statistics.

During external assessments of Principle 8, UIS teams have used the following checklist of good practices to evaluate measures of Indicator 8.1:

- A routine, annual administrative datacollection exercise gathers information on the structure of the education system, students, teachers and examinations.

- Coverage is comprehensive in terms of geographical areas (local, regional, central).

- Coverage is comprehensive in terms of relevant sub-groups of units of collection (e.g. male and female students and teachers, public and private schools, trained and untrained teachers, full-time and part-time students and teachers).
- School list maintenance procedures are adequate (duplicates, confusion in naming, robustness of administrative code, other noticed discrepancies).

- The reporting of age data is reliable.

The UIS staff uses an ordinal scale from 1 to 4 to evaluate the conformity to each established practice:

Practice not observed (scored 1)

Practice largely not observed (scored 2)

Practice largely observed (scored 3)

Practice observed (scored 4). 


\subsection{Producing quality SDG 4 indicators for global monitoring}

The production of high-quality international data and indicators is highly dependent on data quality at the national level, as previously described. International organizations, such as the UIS and the UNSD, and regional organizations such as Eurostat, play a critical role in assuring the production of quality crossnational data and indicators. Often acting as convening agencies for bringing together stakeholders to develop cross-national data, international organizations play an essential role in developing standards, compiling statistics and reporting on the results for key topics of international concern.

Although international organizations follow similar principles for gathering data as national statistical agencies, they face different challenges. Most notably, national authorities are not obliged to report data, given that the provision of international statistics is voluntary. Another challenge is the uncertainty around the quality of the primary data produced at the national level. Data are generally submitted in aggregate form and international organizations lack any influence or control of the production process (other than delivering methodologies and standards and, in some cases, capacity building).

As the official statistical office for UNESCO, the UIS has the mandate to collect education statistics across the world. Its designated role as a custodian agency makes the UIS also responsible for collecting most of the SDG 4-Education indicators. ${ }^{11}$ The UIS develops methods, standards and processes and provides technical assistance to Member States and other international or regional organizations involved in the production of education data.

The UIS plays a vital role within the global education community by engaging in multiple activities that provide quality data of a comparable nature across education systems and countries. These include disseminating international standards such as the International Standard Classification of Education (ISCED), defining and establishing comparable methodology for indicator development, compiling and disseminating international statistics on education through annual data collections directly from Member States or from international organizations and providing technical support to Member States.

The UIS' current statistical work programme is oriented around three pillars as detailed in the UIS Medium-Term Strategy for 2017-2021 (see Figure 5). The work programme is governed by a quality monitoring and reporting framework which guides its internal data production activities. It is based on the IMF's Data Quality Assessment Framework (DQAF), elements of the Eurostat Quality Definition, the UN Principles Governing International Statistical Activities, Fundamental Principles of Official Statistics and the Handbook on Data Quality Assessment Methods and Tools (UNGA, 2014; UNSD, 2013).

Producing the world's most comprehensive database on education statistics, as well as reporting on the new SDG 4 indicators, is complex and multifaceted with multiple stakeholders, processes and data sources. Figure 6 summarises the data production process and interaction between national statistical authorities, regional organizations and the data custodian agencies to produce quality international education data and indicators. Education data from national statistical systems or regional organizations, containing country level data and metadata, flows to the UIS, which is responsible for producing cross-nationally-comparable indicators, calculating global and regional aggregates, and releasing the resulting data and metadata through different dissemination and monitoring mechanisms.

\footnotetext{
${ }^{11}$ The UIS is also responsible for collecting data for other UNESCO programmes including science and technology, culture, and communication.
} 


\section{Figure 5. The UIS Medium-Term Strategy for 2017-2021}

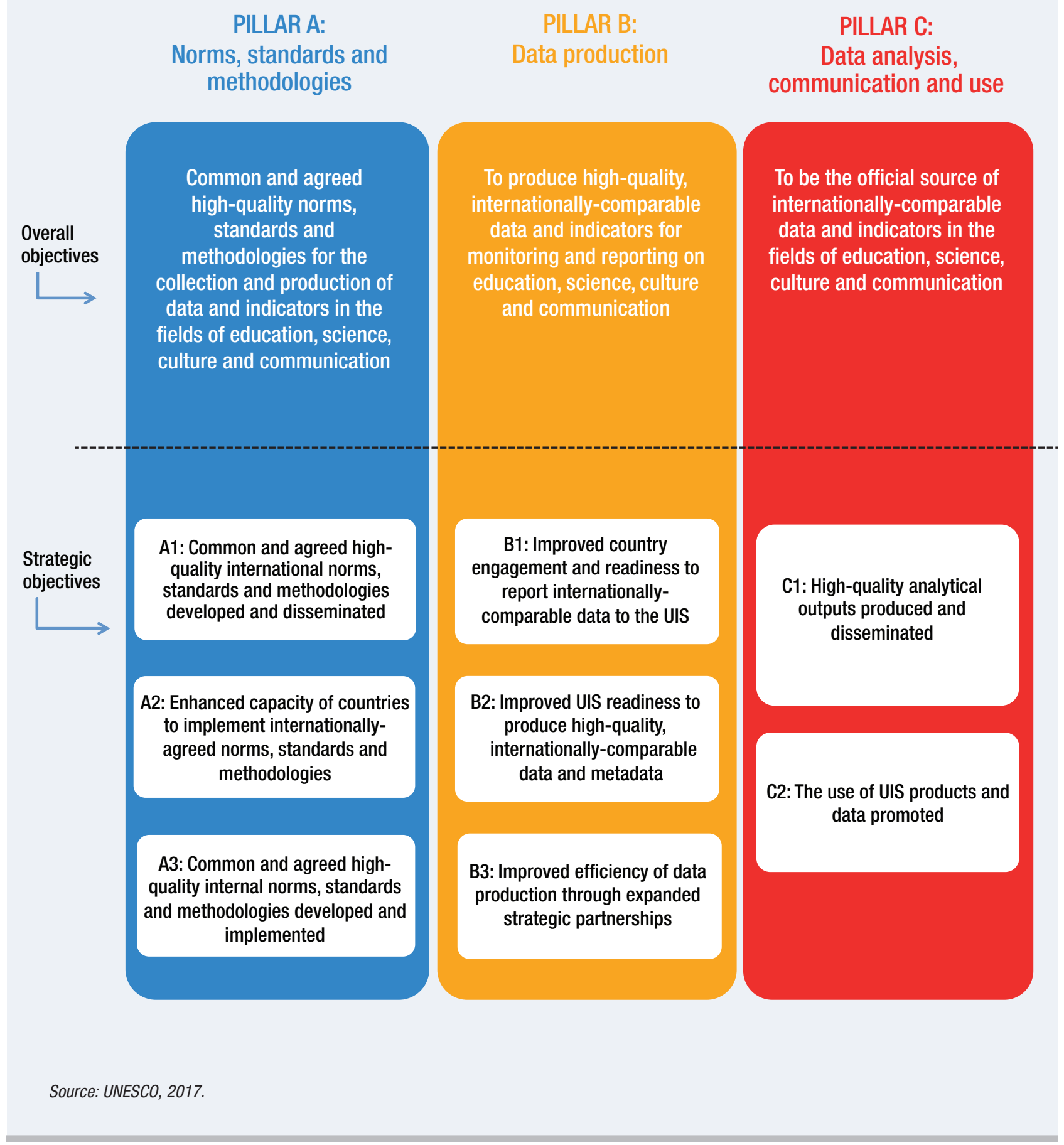




\section{Figure 6. Data flows to produce SDG 4 global indicators}

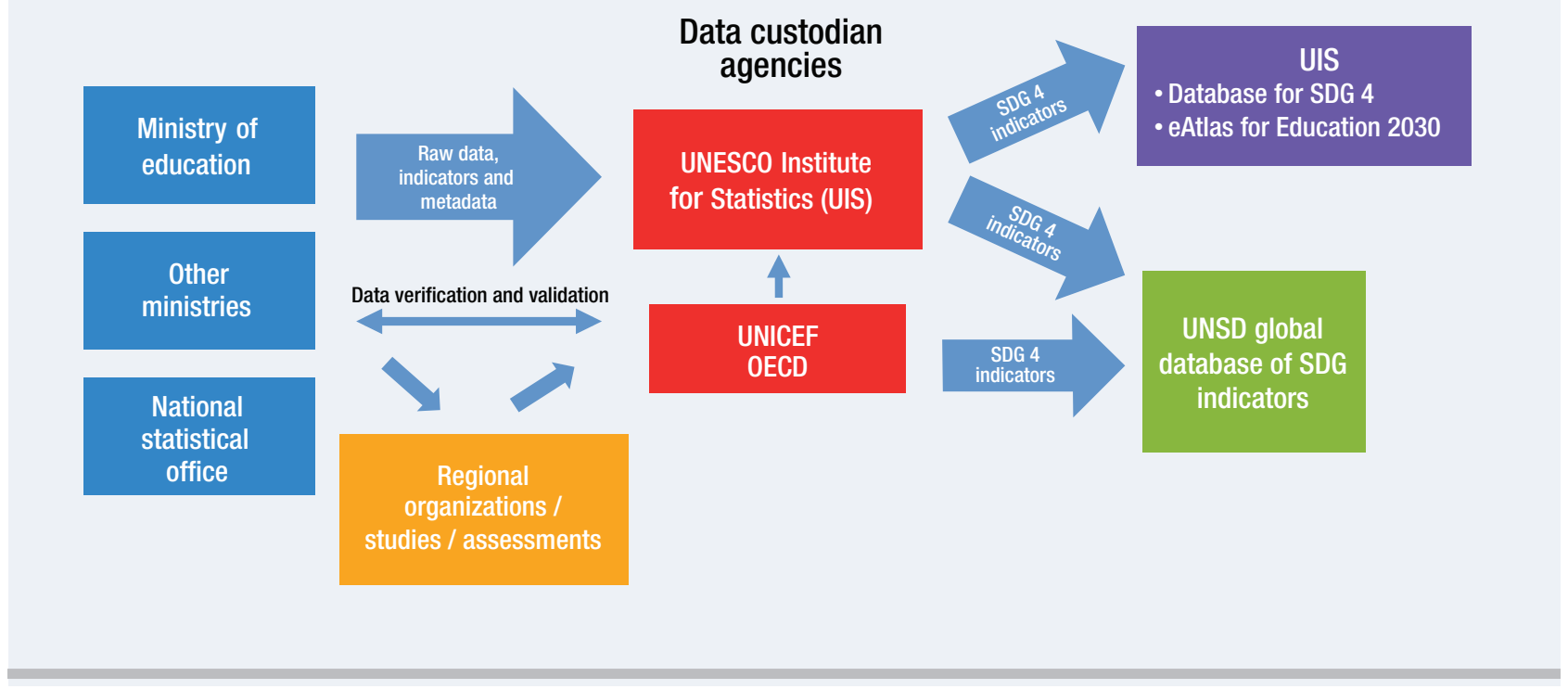

Integrating and harmonising data flows and indicators require systematic and methodical processes at the international level. Data flows from national, regional and international organizations are well defined and based on sound principles in order to produce internationally-comparable, yet nationallyrepresentative, results. The UIS works with regional bodies, such as Eurostat, ECLAC and the OECD to develop and disseminate common methodologies and standards to eliminate duplication and gather data in the most cost effective manner possible.

The SDG 4 indicators are complex in nature and most of them require the establishment of new methodologies, definitions and calculation methods as well as significant changes to the statistical system both nationally and internationally. The data flow process shown in Figure 6 hides the complexity behind the activities required for each step of the production process to report quality international statistics. The three major phases standard setting, data production and data dissemination - are described in the remainder of this section.

\subsubsection{Development of international definitions and standards for producing SDG 4 indicators}

Collecting data from national or regional sources for the purpose of international reporting requires setting up a strong foundation for the production of sound comparable education data. International statistics, like national statistics, require robust frameworks to ensure high-quality outputs and processes. The underlying principles are very similar, but different complexities arise at the global level due to coordination across borders, territories, institutions and governments.

First and foremost, the development of internationally-accepted standards, methodologies, definitions and classifications ensures the compatibility of data across countries, regions and time.

The comparison of national education systems and outputs requires a standardised framework to align national education systems to international definitions. One of the most important tools to achieve this is the ISCED, produced by the UIS, which provides a framework for classifying 
ISCED is a classification system that provides a framework for the comprehensive statistical description of a national educational system and a methodology that translates educational programmes and their resulting qualifications into internationally-comparable levels of education.

ISCED was first established in 1976 by UNESCO Member States to facilitate crosscountry comparisons and benchmark progress on international educational goals. The structure of national education systems differs significantly across countries, for example in defining the age of official school entry, the duration of each level of education and the nomenclature for levels. It effectively provides the ability to translate any national educational system into an internationallycomparable education framework. This mapping process makes data on students and net enrolment rates in primary education, for example, comparable across countries. The most recent version of ISCED was adopted in 2011 and its associated classification of fields of education and training (ISCED-F 2013) was adopted in 2013.

Sources: UNESCO Institute for Statistics, 2012a, 2014.

education programmes and attainment levels according to internationally-agreed categories (see Box 8). The UIS and its partners apply the ISCED standards and methodologies to ensure national data are internationally-comparable and accurate.

The engagement of all stakeholders including government, the private sector and nongovernmental and international organizations in setting definitions and standards for the production of international education statistics is essential to produce high-quality outputs. The UIS develops education data definitions and standards in close cooperation with Member States as well as regional and international organizations engaged in education activities. The UIS promotes this collaboration by working with regional organizations such as Eurostat and the OECD, whose Member States also are engaged in methodological developments. The three organizations collect education data as a joint effort using common questions, standards, methodologies and tools, thereby reducing the burden on the national and international statistical systems.
In 2014, Eurostat, the OECD and the UIS implemented the Statistical Data and Metadata eXchange (SDMX), which consists of technical standards, statistical guidelines and an information technology architecture and tools, into their respective data collections. SDMX collaboration and the establishment of a common definition of data structure, as agreed at the international level, has notable benefits: providing a mechanism to ensure data consistency across international organizations and improving the efficiency of data exchanges and data management processes throughout the statistical data lifecycle.

Regarding SDG 4 specifically, the UIS ran several consultations and convened experts worldwide through the GAML and the TCG to develop well defined conceptual definitions and a standardised methodology for each of the proposed global and thematic indicators. The resulting methodology for the 43 indicators was published in Metadata for the Global and Thematic Indicators for the Follow Up and Review of SDG 4 and Education 2030, which provides, for each indicator, a definition, its purpose, the calculation method, interpretation, 
data sources used for its calculation, required disaggregation and limitations (UIS, 2017e).

\subsubsection{Data collection, processing and validation}

The UIS compiles education related data and metadata from various sources at the national, regional and international level. Although most data are collected through annual UIS surveys sent to Member States, the Institute also produces indicators based on household surveys and international learning assessments as described below:

- Annual surveys. The UIS conducts two global education surveys on formal education programmes and on literacy and attainment, which involve national statistical offices or ministries of education according to the official protocol. ${ }^{12}$ These surveys consist of a set of questionnaires on educational programmes, students, financial and human resources, literacy and attainment, which are based on international standards to assure cross-country comparability. The main data sources are administrative records from school surveys or aggregate data from labour force or household surveys. These surveys are the source of many of the SDG 4 indicators.

- Household surveys. The UIS compiles and disseminates household survey data to produce indicators to examine specific individual characteristics of populations, which are generally only available through these sources. The UIS gathers household survey datasets from international household survey programmes such as the Demographic and Health Survey (DHS) and the Multiple Indicator Cluster Survey (MICS), as well as from survey repositories stored in organizations such as ECLAC, the Integrated Public Use Microdata Series International (IPUMS) and the World Bank. These data are mined to calculate various education indicators, such as attendance and completion rates.

- Learning assessments. The UIS identified nine cross national learning assessments, which meet the criteria for measuring SDG 4 Indicator 4.1.1 (LaNA, PASEC, PILNA, PIRLS, PISA, SACMEQ, SEA-PLM, TERCE and TIMSS), has accessed these data sources and started to calculate some key indicators related to learning outcomes for SDG $4 .^{13}$

Data can be obtained directly by retrieval from a database or running a data collection. For retrieval a formal agreement is made with the relevant organizations and, to run a data collection the standards are embedded in the various data collection instruments (e.g. questionnaires), which are updated to include the necessary input data for calculating the SDG indicators along with detailed instructions and definitions.

Once data are gathered, they undergo a series of checks to ensure quality (see Figure 7).

UIS data analysts review the data to ensure coverage of the entire national education system and compliance with international standards and definitions. Analysts also compare data across several sources, when possible, such as household survey data and any available time series and national statistical yearbooks or databases. Reported data are also compared to other countries in the same region or income group. ${ }^{14}$

\footnotetext{
${ }^{12}$ Member States of the European Union or the OECD take part in the UIS-OECD-Eurostat (UOE) survey.

${ }^{13}$ These are Literacy and Numeracy Assessment (LaNA), Programme d'analyse des systèmes éducatifs de la CONFEMEN (PASEC), Pacific Islands Literacy and Numeracy Assessment (PILNA), Progress in International Reading Literacy Study (PIRLS), Programme for International Student Assessment (PISA), Southern and Eastern Africa Consortium for Monitoring Educational Quality (SACMEQ), Southeast Asia Primary Learning Metrics (SEA-PLM), Tercer Estudio Regional Comparativo y Explicativo (TERCE) and Trends in International Mathematics and Science Study (TIMSS).

${ }^{14}$ See UIS (2017j) for more information on the calculation of national and regional indicators.
} 


\section{Figure 7. Quality assurance in UIS data collection, processing and validation}

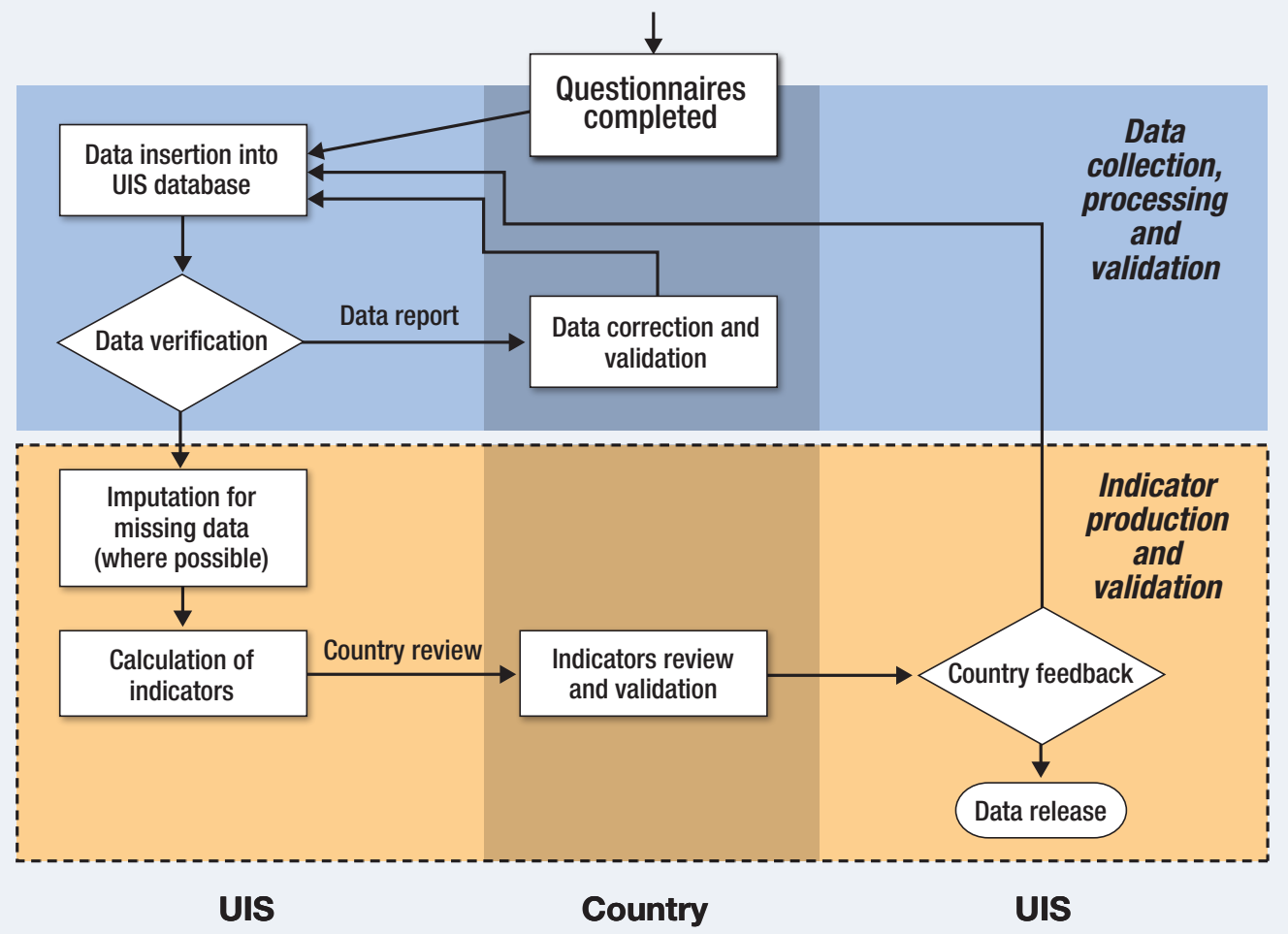

Source: Based on UNESCO Institute for Statistics, 2017j.

The data validation process for administrative data requires documenting all discrepancies or data issues and sending the queries to national authorities for follow up. This review process often entails additional feedback from Member States and another round of data processing. Following the final review, UIS staff confirm the data using the inputs from the respondents and make decisions regarding the quality of the data. If the data quality is deemed insufficient, decisions include suppressing data or replacing them with an estimate or alternate source to produce improved indicators. Estimates are also produced for missing or erroneous data. The UIS produces estimates based on existing data from the current or previous survey, national statistical publications or databases and other reliable sources of data (e.g. household surveys).
The UIS data and indicator production process is transparent and aims to engage national authorities to ensure the data are complete and accurate. Member States are encouraged to make their own estimates in compliance with international standards. National authorities are responsible for the final validation of the data and indicators, including SDG 4 indicators and the full time series.

The validation process is similar for data originating from household surveys or international assessments except that the staff contacts the organization where the databases are housed regarding data issues.

While compiling survey and census data involves several challenges related to data integration and harmonisation, ensuring 
the comparability of learning outcomes is particularly difficult given the diversity of assessments used by countries as well as regional and international organizations. These challenges are related to the differences between three key definitions made by the assessments: first, what and who to assess (conceptual framework), second, how to assess (methodological framework) and finally, how to report the results (reporting framework) (UIS, 2017h). Each of these phases should be carefully examined to design a strategy that produces the most adequate indicators on learning to inform the SDG 4-Education 2030 Agenda (see Box 9).

Once the validation process is completed, the UIS can finalise the production process before publishing internationally-comparable indicators.

\section{Box 9. Challenges in producing indicators on learning outcomes}

There are three key challenges in the production of learning outcomes indicators on a cross-country comparable basis. First, national, regional and global data on basic competencies in literacy and numeracy are frequently collected, but cannot be used in an integrated manner to create a global picture of learning. Second, if national and regional data are to be used to inform the global monitoring of learning, shared technical standards must be developed to ensure that the data are of similar quality.

Third, solutions must take into account multiple viewpoints: identifying globallyrelevant areas of learning that can and should be measured globally; conceptualising how national and regional data can help inform global education measurement; and finally, striking an appropriate balance between global competencies and the role of local influences and goals on education. It will be critical for stakeholders to resolve what can be defined globally through measurement, and what should be left open to local decisionmaking.

Under the coordination of the UIS, organizations participating in the GAML work together to develop:

- The SDG 4 global and thematic indicators related to learning and skills;

- Standards, guidelines and tools to help countries strengthen the implementation of their assessments and evaluate their quality; and
- Capacity development tools to support countries in collecting, analysing and using learning assessment data.

This development work led to several achievements in 2017. From the perspective of availability of new indicators, it was possible to release the first global and regional estimates of children and adolescents not learning, a concrete response to the call to produce data for Indicator 4.1.1. From the methodology development side, there were also important agreements on:

- Organizing the interim reporting of Indicator 4.1.1 in an internationallyconsistent manner for the period 20172019;

- Leveraging all existing data to maximise the number of countries reporting information, including data coming from cross national assessments, but also from those national assessments which provide the exact information the indicators require;

- Continuing the development of UIS Reporting Scales, which enable countries to pursue different options for assessments and set goals for progress, depending on the programme they choose for Indicator 4.1.1 reporting, and yet allow for some harmonisation of the results; and

- Expanding comparability and coverage of learning outcomes measures by designing procedures to link data among the different regional and international assessments. 
Some indicators require that the UIS integrate data from other international sources, as is the case for national population estimates and projections for the calculation of net enrolment ratios, and which are obtained from the UN Population Division in UNDESA. Financial data such as gross domestic product (GDP) and total government expenditure are obtained from the International Monetary Fund (IMF), the UNSD and the World Bank. The UIS also calculates aggregates based on country classifications by region, sub-region and income.

\subsubsection{Dissemination}

Once the data production phase is completed, the UIS is mandated to make the education related data widely available at no cost to UIS clients and data users. The dissemination of SDG 4 indicators - as well as other education indicators creates the necessary link between data and evidence based policymaking. Data are often used to assess past and current trends in education, prepare forecasts for future trends, inform national policy planning and make thematic analyses of education systems and policies. With quality education data available at the international level, cross-country comparisons and regional trends are used to measure progress made against the SDG 4 and its targets.

Data products must be easily understood and include all relevant metadata to ensure clarity. By engaging directly with data users to ensure the relevance of UIS data collections and making UIS data readily available, the UIS reduces the burden of responding on Member States.

The UIS has focused on several dissemination mechanisms to make a positive impact on the availability of SDG 4 education data for policymakers and analysts.

- Sharing SDG 4 data. While the UIS regularly publishes education data online in the UIS database, the UIS website also has two specific platforms dedicated to the publication of SDG 4 data: the eAtlas for Education 2030 and the SDG 4 microsite. ${ }^{15}$ Launched in 2016 , the eAtlas is a tool to present the global and thematic indicators through user-created maps that can be downloaded including the data tables used for their design. The SDG 4 microsite shares the latest education initiatives, analyses and trends produced by UIS. One objective of the Medium-Term Strategy is to improve the connections between the UIS data, glossary and methodologies as well as improving the user interface of the UIS database.

- Analysing the SDG 4 indicators. In addition to sharing tools and methodological documents, the UIS produces a collection of analytical reports on specific SDG 4-related themes using the data. ${ }^{16}$ The UIS also provides the GEM Report with the SDG 4 official data for the purposes of analysing global and regional trends in the annual publication, which has the mandate of monitoring the education goals. The 2017 and 2018 GEM reports will include analyses related to accountability and transparency in education and migration and displacement, respectively.

- Incorporating global indicators into the UN database. The UIS contributes education data and its methodologies (SDG 4 only) to the UNSD's SDG Indicators Global Database. ${ }^{17}$ By participating in this process, the UIS is ensuring that education data are available to non-education specialists and are incorporated into global thinking about the SDGs.

In addition to these SDG related dissemination paths, UIS data are published in reports and used for analytical and other purposes by international and regional organizations. These include the United Nations Development Programme (UNDP), UNICEF and the World Bank. The Global Partnership for Education (GPE) also relies on the UIS education data to inform the international education agenda.

\footnotetext{
${ }^{15}$ Respectively available at http://on.unesco.org/sdg4-map, http://uis.unesco.org/en/topic/sustainable-development-goal-4 and http://data.uis. unesco.org

${ }^{16}$ For example, see the UIS report on the global learning crisis, UIS (2017f).

17 https://unstats.un.org/sdgs/indicators/database/
} 


\section{Supporting the development of national statistical capacities to monitor SDG 4}

Based on the mandate of the UIS to collect, compile and disseminate of internationallycomparable data, developing statistical capacity would mean ensuring that countries understand the importance of comparability and comply with their commitment to maintain data quality. Therefore, UIS support should ensure that Member States:

- Clearly understand data requirements, indicators, methodologies and data sources to produce quality data for national and international monitoring;

- Set up a strong mechanism at the country level with a clear mandate to collect quality data from various sources; and

- Have data ready for dissemination for national policymaking and stakeholder use.

Given the complexity of the required SDG 4 data, and the need to improve their availability and quality, the implementation of a quality driven data framework to monitor SDG 4 will present a challenge for countries at all levels of development. The UIS is fully engaged in strengthening national statistical capacities through an inclusive approach, articulated around the mobilisation of national commitment, donor support as well as national and regional partnerships.

The UIS approach is driven by countries' needs and demands with a clear definition of their policy priorities, which should be reflected in a National Indicator Framework (NIF) for education. This tool is used to determine the data needs for monitoring from a national perspective and should be the initial point for starting any plan to improve the information system on education and data collection. Aligning the NIF with international indicator frameworks has the potential to streamline data collection, meet international definitions and standards in education and integrate the SDGs into national planning processes.

Figure 8 presents an overview of the UIS model for capacity development support. This figure shows the various stages in the sequential process, based on UIS engagement with national statistical systems across multiple objectives, including mapping of stakeholders and data sources, assessing data quality, and defining a national data strategy and improvement plan. From the onset, the role

Figure 8. Capacity development model

Formulation of the

National

Indicator

Framework (NIF)
Data mapping
Data Quality

Assessment

Framework (DQAF)
Development of the NSDES 
of the UIS is balanced between knowledge generation and engaging stakeholders, development partners and policy decisionmakers as a strong prerequisite for national ownership and sustainability.

UIS capacity development work will be guided by three principles:

- Partnership development. The UIS approach to the challenge of monitoring the SDGs requires strong partnerships amongst different actors at the global, regional and national levels to ensure the sustainability of capacity development efforts. International and regional partnerships can help avoid the duplication of different partners' support to a country and render their assistance and involvement more efficient.

- National ownership. National ownership of the plan is key for an effective capacity development strategy and requires that national stakeholders generate country priorities.

- Holistic approach. Statistical capacity development needs to avoid fragmented efforts and consider developing capacity in a holistic manner, from institutional capacity to organizational and individual capacity development.

The model begins with the mobilisation of national commitment and donor support, follow by the assessment of capacity needs and ends with the development of a costed action plan to be implemented by the countries in collaboration with regional and national partners (see Annex 3).

The UNSC recognised the need to build statistical capacity to monitor the SDGs and established the High-Level Group for Partnership, Coordination and Capacity Building for the 2030 Agenda (HLG-PCCB). Its members include chief statisticians from 23 national statistical offices, representing countries in their respective regions. The mandate of the HLG-PCCB includes the recent production of the Cape Town Global Action Plan for Sustainable Development Data, which outlines the necessary standards and actions to adequately build statistical capacity to monitor the SDGs. The plan is based around six strategic areas, which focus on concerns such as coordination and governance for national statistical offices, modernisation, data harmonisation, dissemination, a holistic approach to data development and the mobilisation of resources to enable the plan (Keijzer and Klingebiel, 2017). It recommends the development of "action plans to improve the availability and quality of sectoral data and indicators" to monitor the implementation of the SDGs (HLG-PCCB, 2017).

In this context, the UIS has also been in discussions to engage in a collaboration with the Partnership in Statistics for Development in the $21^{\text {st }}$ Century (PARIS21) regarding the linkage between the National Strategies to Develop Statistics (NSDS) and sectoral statistical strategies. This has been the basis for the development of a new project carried out to design and implement SDG 4 pilot monitoring initiatives in low- and lower-middle-income countries in Africa and Asia within the UNESCO Capacity Development for Education (CapED) Programme. The first imminent concrete collaboration will be in one of the ten CapEd pilot countries (Montoya and Naidoo, 2017; PARIS21, 2017).

The rest of this section, below, is set forth around the main UIS actions described in Figure 8 to support and assist countries in terms of setting standards and developing high-quality monitoring frameworks specifically for SDG 4-Education 2030. It is presented in three main sections, namely around the improvement of the NESS, the mapping of data sources and availability of information and the quality assessment of the SDG 4 information sources.

\subsection{Designing and implementing a National Strategy for the Development of Education Statistics}

The 2030 Agenda and the Education 2030 Framework for Action explicitly call upon the UIS to play a key role in providing technical expertise to build and strengthen country data systems, particularly in low- and middle-income countries (UNESCO, 2015, para. 98). 


\section{CoP Code of Practice \\ DQAF Data Quality Assessment Framework \\ NESS National Education Statistical System \\ NIF National Indicator Framework \\ NSDES National Strategy for the Development of Education Statistics \\ NSDS National Strategies to Develop Statistics}

The coordination among the various data sources (primarily administrative, household surveys and learning assessments) within a country remains one of the main challenges in the production of quality data for SDG 4 . The different entities generating each data source usually do not work in a coordinated fashion. In many countries, data collection methodologies and raw data are not always shared among the entities, so that, effectively, data cannot be linked across schools, households or individuals, for example. The existence of data silos creates analytical gaps in understanding the progress of education. There are also concerns about partial data that do not give the full picture of a sector or sub-sector. Moreover, data collection processes in developed and developing countries are not always harmonised and, subsequently, can create confusion.

Given the challenging requirements of SDG 4 monitoring and data development, there is an urgent need for a coordinated approach involving all data providers, the main data users as well as national, regional and international partners. NESS stakeholders, which have a mandate to produce official statistics for policy and planning, should be able to produce and share quality, relevant statistics from multiple data sources through a coordinated national effort aimed at improving the mechanisms and processes for data production. In practice, however, NESS consists of discrete information systems working in isolation for the production of data in each sub-sector (e.g. early childhood, basic education, technical and vocational education and training, tertiary education) (see Section 2.2).

The UIS supports the development of a sector wide approach to education statistics in order to strengthen the statistical capacity of NESS to produce data to monitor SDG 4. The NSDES

Figure 9. Organization of National Strategies for the Development of Statistics

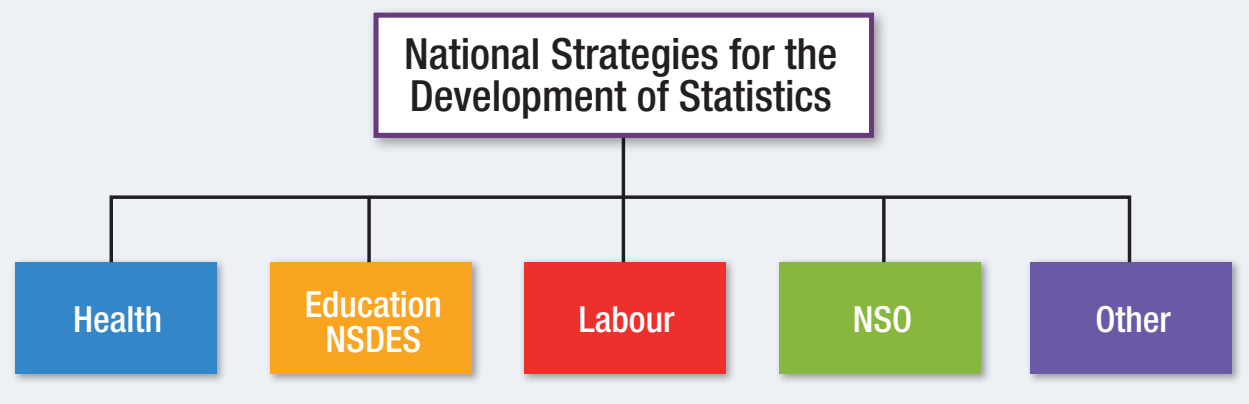


is a powerful policy instrument designed by government and its partners and provides a roadmap for developing NESS based on a holistic education data strategy. The NSDES aims to provide a medium term vision for where the NESS should be in five to ten years, sets milestones for getting there and fully integrates it into the broader NSDS. Figure 9 shows this relationship, whereby the NSDES sits as one of the sectoral strategies for the development of statistics on the basis of which the multisectoral NSDS could be developed (HLG-PCCB, 2017; PARIS21, 2017).

The development of the NSDES is a participatory exercise that reinforces synergies among all education data producers and users. The CoP and the DQAF (see Section 2) are central elements of the NSDES development process, serving as diagnostic tools to assess how quality is assured and how quality performances can be monitored through the NESS. The development of the NSDES should meet several criteria. It should be:

- Integrated into a preparation process as required by the NSDS, if it exists;

- Ensure that the development of education statistics is fully integrated in national planning for statistical capacity development;

- Reflect the education data needs resulting from policy priorities and its objectives, including regional and international commitments;

- Serve as a framework for international and bilateral assistance;

- Allow an appropriate monitoring and evaluation process to take place;

- Include all aspects and units of the data production chain, bring together data users and producers and address the issues related to the analysis and use of data; and

- Be included in the overall Education Sectoral Development Plan.
Using a sectoral approach to education, the NSDES should include:

- Statistical production activities necessary to produce the required data for monitoring national, regional and global education goals; and

- Capacity-development activities to ensure that data are produced according to recognised quality standards.

The NSDES is based on a sound country led analysis of the current NESS situation initially in terms of data availability, then using a data quality assessment of the various data sources and considering suggestions for improvement. The NSDES includes a monitoring and evaluation framework to effectively track implementation. It should be, if possible, integrated into national education sector plans (see Box 10).

The NSDES is developed and implemented through a National Expert Group on Education Data (NEGED), which provides a space for dialogue between government and partners to improve support (Montoya and Naidoo, 2017). The NSDES is structured within a results-oriented framework (including related costed plans) and should be linked to national planning documents. In many countries, however, the coordination and integration of the education sector in the NSDES is weak, not effective and in need of an adequate technical and institutional setting. The participation of development partners in the NEGED, through which synergies could be built, is a potential avenue for international and bilateral assistance.

Before a country embarks on data collection, it must determine its data requirements to produce each of the SDG 4 indicators (see Sections 2.2 and Section 3.2 on metadata). A careful mapping of data needs, the availability of data and assessments of the quality of data sources are therefore critical for designing a successful strategy to strengthen the NESS, including the designing/development of a capacity development programme. 
National education plans and policies often state the country's goals for solving the challenges faced by the education system. One aspect of implementing the plans and policies should be the regular monitoring of the progress achieved since the beginning of the planning period. A monitoring framework with a set of indicators can provide quality information to meet those analytical needs.

The set of indicators used to monitor education objectives should be linked to the policy priorities established by the governments. Considering that countries usually have a wide set of national education priorities, and have adopted SDG 4 and possibly other supra national development agendas, they are faced with the tremendous challenge of producing different data and indicators to inform several monitoring levels. Thus, countries need to improve the alignment of data demands and reinforce the synergies among all education data producers and users. In turn, this will improve the quality of education data as a tool for policymaking and monitoring while reducing the burden of data reporting.

\subsection{Mapping data sources and the availability of information}

The identification of data sources and the availability of information provides relevant elements for analysis and understanding of a country's current capability to generate SDG 4 monitoring indicators. The data mapping exercise should be based on the National Indicator Framework (NIF), derived from national policy priorities, and includes the data demands implied by the global and thematic indicators, insofar as they are acknowledged by, and relevant to, the country.

Once data requirements are determined by the $\mathrm{NIF}$, countries need to undergo an analytical process to review if the country is implementing the surveys needed to provide the data. Quality data should satisfy the concept, definitions and methodologies of the indicator, and comply with other characteristics, namely the frequency of the data and its capacity to be disaggregated by age, sex, location, income, ethnicity, migratory status and disability to respond adequately to the SDG's fundamental principle of "no one left behind" (UNSG, 2016). Data gaps are of a particular concern to the quality of SDG 4 indicators. As previously stated, the UIS has calculated that the world gathers only about one-half of the data needed to monitor progress towards the SDG 4 targets (see Section 1.3). ${ }^{18}$

The SDG 4 Data Mapping Questionnaire is specifically designed to assess data availability and collect the information necessary to produce the proposed indicators for monitoring SDG 4-Education 2030 goals. The data are used to produce a detailed Mapping of Data Availability to Monitor SDG 4 (UIS, 2017a). This initial inventory of a country's data availability is the basis for starting a planning process to strengthen national information systems related to SDG 4. The information collected in the inventory helps to identify potential data gaps and areas requiring further development. It also informs the development of an action plan for improving data

\footnotetext{
${ }^{18}$ Regional reports on data availability have been published for the Arab States, Asia and the Pacific, Latin America and the Caribbean and subSaharan Africa and are available at http://uis.unesco.org/en/topic/sustainable-development-goal-4
} 
quality and developing national capacities to align and strengthen national data and EMIS.

The tool developed by the UIS to map data availability standardises the identification of data items and sources relevant for SDG 4 indicators and includes a Results Reporting Template (see Table 2). The aspects covered by the SDG 4 Data Mapping Questionnaire are:

- Data availability and possibilities of disaggregation by SDG 4 indicator;

- Brief characterisation of each relevant national statistical source;

- Identification of possible sources in which missing required data could be collected; and

- Participation in regional and international surveys.

Together, these elements map existing data sources whose quality should be assessed afterwards through standardised tools built around a framework that integrates the key quality principles of the UIS presented in Section 2.1. The main data sources required to populate the SDG 4 monitoring indicators - that is, administrative data, financial data, household surveys and learning outcomes - will be assessed with the aim of identifying what actions could be undertaken to improve the current situation.

\subsection{Assessing the quality of SDG 4 information sources}

The UIS reviewed the structure and implementation modalities of the DQAF derived from the initial adaptation of the existing IMF-DQAF tool for education data. The UIS used the Ed-DQAF extensively for a series of country diagnostic assessments of national education statistical systems in Asia, Latin America and the Caribbean and sub-Saharan Africa. It is considered one of the main pillars for UIS national capacity-building activities.

The Ed-DQAFs were implemented initially in Latin America and sub-Saharan Africa between

Table 2. Extract of the Results Reporting Template for the SDG 4 data mapping questionnaire

\begin{tabular}{|c|c|c|c|c|c|c|c|c|}
\hline Target & Indicator & Availability & $\begin{array}{c}\text { Last available } \\
\text { data }\end{array}$ & By age & By sex & By location & By wealth & By disability \\
\hline \multirow{2}{*}{4.1} & 4.1 .1$. & Yes & 2014 & $\mathrm{X}$ & $\mathrm{X}$ & $\mathrm{X}$ & & \\
\hline & 4.1 .2$. & Partial & 2015 & & & & & \\
\hline & 4.1 .3$. & Yes & 2015 & & $\mathrm{X}$ & & & \\
\hline & 4.1 .4$. & Yes & 2015 & $\mathrm{X}$ & $\mathrm{X}$ & $\mathrm{X}$ & & \\
\hline 4.1 .5$. & No & & & & & & \\
\hline & 4.1 .6$. & Yes & Miss & & $\mathrm{X}$ & $\mathrm{X}$ & & \\
\hline 4.1 .7$. & Yes & 2013 & & & & & \\
\hline $4.1 . \mathrm{X}$ & & & & & & & \\
\hline
\end{tabular}

Source: UNESCO Institute for Statistics, $2017 a$. 
2005 and 2006. The UIS, in coordination with the UNESCO office in Dakar (formerly BREDA), conducted a total of 19 assessments in subSaharan Africa with some modifications to the methodology - between 2008 and 2011 - and most recently in Cameroon and Benin in 2012 and 2013, respectively. These assessments provided national and regional support to the African Union Second Decade of Education (2006-2015) Action Plan, the Southern African Development Community's education programme and the Economic Community of Central African States. Between 2008 and 2011, the Ed-DQAF (an original and a revised matrix) was applied in 15 Southern African Development Community (SADC) countries and the recommendations were largely applied by governments to improve their EMIS. Within the framework of a project funded by Australia's Department of Foreign Affairs and Trade (DFAT), the revised Ed-DQAF was used in six countries in the Pacific region for the development of action and improvement plans and for resource mobilisation. In order to expand the national use of the tool to self-assess the EMIS, a web-based DQAF was developed for 11 other countries in the region and used to identify common solutions responding to main quality issues (UIS, 2017g).

The UIS is promoting the adoption of the CoP to guide the development of a better quality of data by implementing source-specific Ed-DQAFs. Each targeted tool assesses administrative data, household survey data, government expenditure on education and learning outcomes data: the assessment results will feed into the UIS supporting strategies to the NESS.

\subsubsection{Data quality analysis of administrative routine systems}

Administrative records are the source of 27 monitoring indicators for SDG 4 and supply information on students, teachers and institutions (see Table 3). These data are collected at the school level, reporting up the administrative chain to the national ministry or statistical office.

The data are used by ministries of education for management, planning purposes and/or statistical purposes, and are typically updated on a regular basis. Most of the international monitoring indicators for the previous global development agenda were based on administrative data produced by countries and compiled by international organizations.

In the context of the SDG 4-Education 2030 Agenda and the emergence of country needs to strengthen their NESS, the Ed-DQAF required a major overhaul to meet the new challenges. Specifically, the Ed-DQAF needed to be reviewed in terms of content, structure and implementation modalities. The original Ed-DQAF was slightly burdensome in terms of use, and some concepts needed adjustment. Based on the review, the UIS produced a new light Ed-DQAF" in May 2017 with a reduced matrix, while keeping most of the initial dimensions of the quality framework (see Box 11). National statistical teams and experts can make use of the light Ed-DQAF as a self-assessment tool following recognised standards and for all types of data sources (i.e. education administrative records, school censuses, household surveys, learning outcomes assessments, educational finance data).

Table 3. SDG 4 indicators by data source

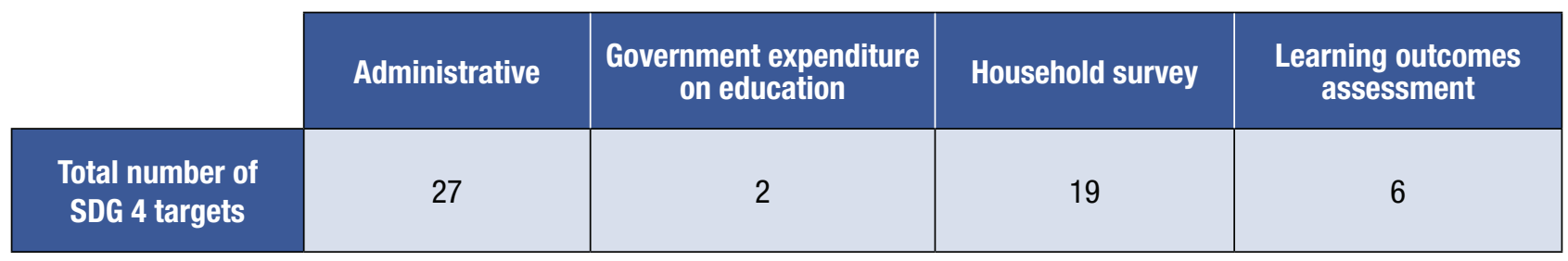

Note: See Annex 4 for detailed information per SDG 4 target. 
In 2004, the UIS undertook initial work with a group of experts from the World Bank to adapt the existing IMF DQAF3 tool specifically for education data. The Ed-DQAF - a matrix of 140 quality items structured under six dimensions of quality - was used for a series of country assessment exercises in developing countries. In an attempt to make the tool a public good, an online documentation Wiki portal was developed to centralise all existing documentation and give access to all EdDQAF reports and other related materials.

In the context of the SDG 4-Education 2030 Agenda and the UIS capacity-building strategy revision, national statistical teams required a lighter tool for self-assessment that still followed recognised standards. Consequently, the Ed-DQAF tool was revisited to focus specifically on administrative routine education data systems (while other tools were being developed for education data collected through household surveys and for learning assessment studies). In addition, it focused on the self-assessment criteria,

Source: UNESCO Institute for Statistics, 2012b, 2017b. ensuring that evidence for assessment could realistically be identified by national teams for each of the selected data quality items. The new "light Ed-DQAF" retains 46 of the 140 items from the initial matrix. The new matrix includes practical scoring guidance for each data quality item, thus facilitating selfassessment by national teams. It provides guiding elements for the structures in charge of producing appropriate and reliable data that adhere to internationally-recognised professional and scientific standards.

The CoP was also adapted into a shorter light version, and operationalised under the light Ed-DQAF. Similar to the full CoP with 12 principles (see Box 6), the light version has 8 principles and 21 indicators covering the institutional environment, statistical production processes and statistical outputs: policy and legal framework, adequacy of resources, relevance, sound methodology, accuracy and reliability, periodicity and timeliness, consistency, and accessibility and clarity (see Annex 1).

\subsubsection{Data quality analysis of sources of government education expenditure data}

Expenditure data include information on government spending on education from budgetary execution reports. Examples include construction and maintenance of schools and teacher salaries. With regard to education financing data, the UIS designed three tools to help countries map education financing flows, list the sources of data available for monitoring education financing and assess the quality of education finance data. The three complementary tools, designed to be used in the following sequence, are referred to as the Education Financing Flows Mapping, the Data
Sources Matrix and the Data Quality Assessment Framework: Government Education Expenditure Data Sources (hereafter, DQAF-Finance tool). ${ }^{19}$

In June 2017, the UIS developed the DQAF Finance tool to help education officials critically assess the quality of data produced by their counterparts in the finance ministry, and serve as a means to engage with them. The objective of the DQAF-Finance tool is to use the main administrative DQAF tool and adapt it to assess the quality of data on education financing from government sources. The relatively short, 12-question matrix is organized along the same main three broad areas - institutional environment, statistical production processes

\footnotetext{
${ }^{19}$ The DQAF-Finance tool is derived from the light Ed-DQAF for administrative data.
} 
and statistical outputs - and focuses on how government finance data can be used by education stakeholders (see Annex 5). As such, it does not aim to assess the overall quality of government financial systems.

The tool assesses how quickly and easily financing data are made available to education statisticians and policymakers and whether they can be disaggregated in a way which is relevant to the education sector such as by level of education or spending category (e.g. schoolbooks). It is also intended for use in conjunction with the Education Financing Flows Mapping and Data Source tools created by the UIS, which assess who funds education in a country (and how) and what data sources exist for each. The combined results of the three assessments should include corresponding recommendations and actions to resolve the outstanding issues, and should be included for consideration in the NSDES.

\subsubsection{Data quality analysis of household surveys}

Household surveys are the source of 19 monitoring indicators for SDG 4 (see Table 3). Despite the diversity of household surveys, they usually provide demand side information on education, such as the participation and completion (as well as non-participation) of the population, educational attainment among adults and literacy rates. Large international household surveys, such as UNICEF's MICS and the DHS, are valuable in producing statistics about learning opportunities for children before entry into primary school. ${ }^{20}$ These two surveys are particularly good sources for producing key education statistics, given the wealth of the surveys' socioeconomic data and other information about households. Some international and national household survey programmes also collect data on reading and mathematics basic skills, such as, notably, the current round of the MICS. Some household surveys are focused on education, such as the DHS EdData Household Surveys.
More common, however, are household surveys covering multiple topics, with education as one of many subjects of interest. Education data from household surveys are used to complement national administrative data, especially with regards to the disaggregation of data for various groups, including out-of-school children. ${ }^{21}$ Household survey data are used widely in national education planning documents as well as in intra- and cross-country comparisons made by UNICEF, the UIS, the World Bank and other providers and consumers of education statistics.

For education purposes, it is important to assess the quality and sustainability of the household survey data on education. Key questions include, for example, whether the right data are collected, whether they are sufficiently reliable and whether they are representative of the population.

The UIS has designed a tool for assessing household survey education data, closely aligned with the DQAF for administrative data and which follows the same eight main CoP principles described in Box 11. The DQAF for household survey data (DQAFHHS) tool, which helps countries assess the utility of various household data sources for use in education statistics, consists of two spreadsheets. The first spreadsheet collects information on the institutional environment and resources, and is common to all surveys within a country. The second collects background information specific to the household survey and includes information on statistical processes and statistical outputs.

As such, the DQAF-HHS includes aspects that are shared with the Ed-DQAF on administrative data, but focuses on survey specific aspects related to data collection, analysis and dissemination. This applies in particular to Principle 5 (Accuracy and reliability), which records information on sampling, population coverage and options for disaggregation.

\footnotetext{
${ }^{20}$ The DHS programme is implemented by ICF International and funded by the United States Agency for International Development (USAID).

${ }^{21}$ Data from household surveys are usually disaggregated by sex, age, location and wealth, sometimes by ethnicity and mother-tongue language, and rarely in terms of disabilities (the current MICS Round 6 adds this data).
} 


\subsubsection{Data quality analysis of learning outcomes assessments}

One of the core components of the SDG 4Education 2030 Agenda is that children and adults attain a minimum level of knowledge and skills in certain learning domains, namely reading (or literacy), numeracy, being developmentally on-track (for early childhood), technical and vocational skills, environmental science and geoscience (for 15-year-olds) as well as knowledge and skills to promote sustainable development. In total, six indicators are likely to come from learning outcomes assessments as defined by Targets 4.1, 4.2, 4.4, 4.6 and 4.7. ${ }^{22}$ Reporting progress towards these targets requires regularly producing indicators to measure those areas: large-scale assessments are important instruments for establishing and monitoring education quality at the system level.

Large-scale assessments focus on defined learning domains (e.g. reading, mathematics), usually measured against the knowledge required by the national curriculum at specific grade levels and defined in the assessment framework. They aim to answer the question as to whether the learner can apply skills and concepts acquired in the classroom. Learning assessments can be international, regional or national in scope, focus on a particular population (i.e. by age or by grade level) and can be sample-based or conducted as a census.

To be effective, large-scale assessments need to gather data that provide an accurate reflection of the present situation. As such, the management of data quality plays a central role in SDG 4. At the national level, this involves the development of national strategies for large-scale assessments, education data and the commitment to building assessment and statistical capacity. At the international level, this involves a participatory approach to the development of international standards and methodologies, the provision of diagnostic tools and guidelines, and support in capacity development (UIS, 2016).
In consequence, the UIS proposes a framework to guide the design and implementation of learning assessments so as to support the production of measures of learning outcomes according to the highest-quality technical standards: the Principles of Good Practice in Learning Assessment (GP-LA) is a central element in the international commitment to the management of SDG 4 data quality for learning outcomes (UIS and ACER, 2017). The GP-LA is an articulation of good practices that can work with the diversity of large-scale learning assessment activities being undertaken worldwide. Within SDG 4 reporting processes, the GP-LA serves two purposes:

- First, it serves as the conceptual framework to evaluate the quality of large-scale assessments and data from these assessments submitted for SDG 4 reporting. By outlining key principles of assessment quality, the GP-LA helps countries achieve technical rigour with sufficient flexibility to set their country-specific assessment priorities.

- Second, the GP-LA principles, complemented with the corresponding code of practice, will support the diagnosis of country-level capacity to develop, implement and use data from large-scale assessments. In a case where large-scale assessment data submitted for SDG 4 reporting do not meet the required reporting standards, the GP-LA will inform the formulation of capacity-development plans and help target technical support.

The GP-LA is a statement of principles, designed to be advisory for developing and implementing assessment programmes. The statements are deliberately general in nature so that they are applicable to various large-scale assessment contexts and settings (e.g. with international, regional or national focus, school-based as well as household-based assessments). In this way, the GP-LA constitutes the conceptual framework to develop an assessment of data quality for that type of study.

\footnotetext{
${ }^{22}$ These correspond to indicators 4.1.1, 4.2.1, 4.4.2, 4.6.1, 4.7.4 and 4.7.5.
} 
Based on the conceptual framework proposed by the GP-LA, the UIS is developing a methodology known as the Data Alignment process to obtain cross-national comparable information necessary for monitoring learning outcomes for SDG Indicator 4.1.1 (see Table 1). The Data Alignment process will enable education systems to examine and report on the current level of alignment of national assessment programmes with the UIS Reporting Scales (see Box 9) and will be implemented in six steps (UIS and ACER, forthcoming):

1. Country's awareness of international consistency in reporting learning outcomes: Country gains familiarity with the definition and description of the UIS Reporting Scales, the content coverage, domains, strands and levels.

2. Country preparation of databases and materials: Country compiles their crossnational and national learning assessment frameworks, test blueprints, items, item responses, micro database, codebooks, operational manuals and assessment results.

3. Conceptual alignment: This defines the specific concept-based alignment of the assessment programme with the UIS Reporting Scales, per domain (e.g. mathematics, reading). Within each domain, alignment is verified within strands (e.g. core components which reflect knowledge, skills and understanding) and for levels of learning progress for each strand and for the entire domain.

4. Assessment of procedural consistency: This step enables the UIS to collect basic procedural information from education systems about the data that are provided for reporting SDG Indicator 4.1.1, and to understand the level of confidence with which results can be reported.

5. Validation and reporting: A validation process including most critical components of the conceptual alignment and the assessment of procedural consistency is implemented, with support of an external evaluator, before submitting the information for global reporting of the indicator.

6. Improvement plan and capacity development: The Data Alignment process will generate statements about any limitations in alignment with the UIS Reporting Scales. This information is intended to assist a country in working towards improved accuracy in reporting for SDG Indicator 4.1.1. The UIS's work programme through the GAML includes additional tools and processes to assist countries in planning capacity-building activities.

\subsection{Towards a coordinated approach to education data production}

The set of tools described in the preceding parts of Section 3 was designed by the UIS to accompany national statistical systems in their plans to improve the quality of education data produced nationally and internationally to monitor SDG 4 (see Figure 10).

The UIS works in a coordinated manner by developing the technical capacity of countries' statistical teams to develop a plan to improve the NESS. In that plan, the formulation of the NIF is the starting point that will determine the data needs. Then, by implementing the Data Mapping Questionnaire and the various DQAFs, countries can generate most of the inputs needed to feed the development of a NSDES for policy and planning purposes, thereby building quality data into part of a larger coordinated statistical system.

The CapED SDG 4 pilot initiative was launched in mid-2016 within UNESCO's CapED Programme. Its objective was to develop national capacities to integrate SDG 4 into national education policy and sector management including monitoring of progress towards SDG 4.

The CapED SDG 4 initiative provides a platform for testing and implementing this approach and the associated tools in a group of selected low- 
and lower-middle-income countries. The ten pilot countries which are being assisted by UNESCO are: Afghanistan, Cambodia, the Democratic Republic of the Congo, Haiti, Madagascar, Mali, Mozambique, Myanmar, Nepal and Senegal. The UIS, as part of UNESCO's implementation team on the project, has developed training materials on how to use the data monitoring tools. The UIS works in partnership with the countries in a "learning by doing" process, using simple tools, which can be adapted according to the national context. (Montoya and Naidoo, 2017).

\section{Figure 10. UIS components to support national education data production and tools}

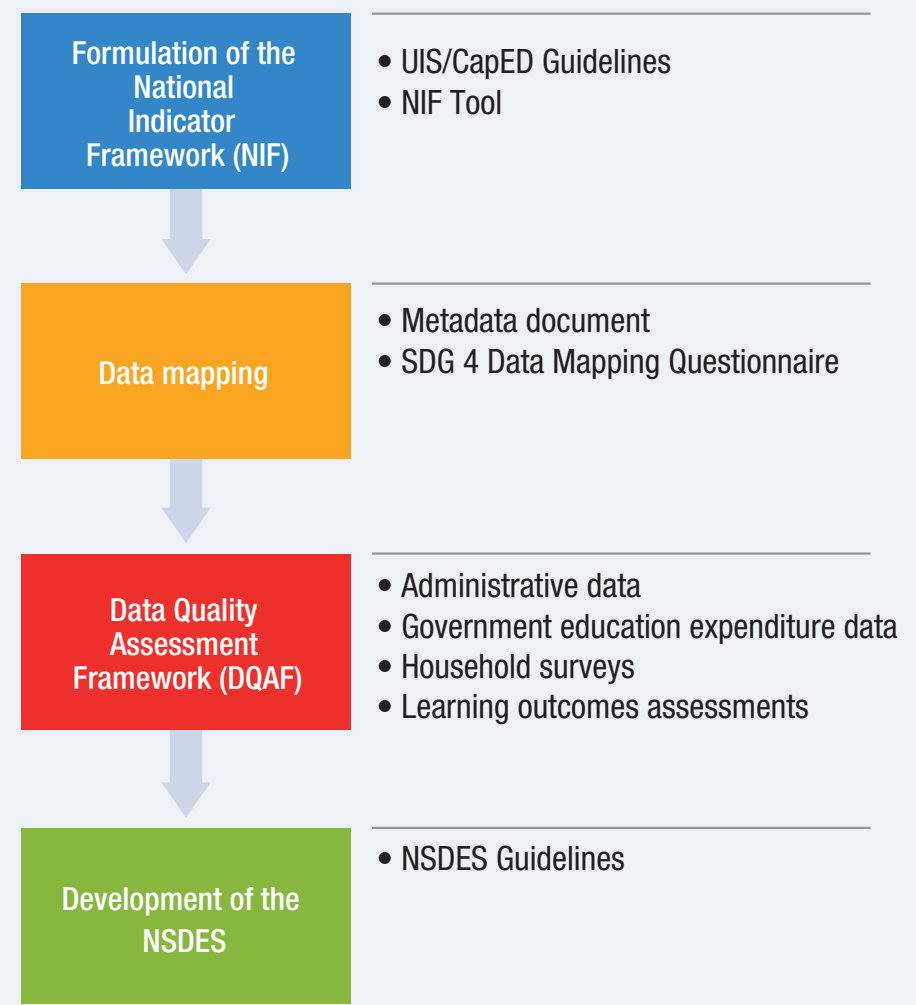




\section{Conclusions}

In the past year, the UIS and its partners have continued leading the implementation of the global and thematic indicators that were agreed upon to monitor the SDG 4-Education 2030 Agenda. It has moved forward in the development of standards and specific tools to support and strengthen national education information systems to respond to new monitoring demands.

This report positions data quality as a crucial aspect of the implementation strategy of the monitoring frameworks. Thus, it has proposed an approach to define data quality and has identified a pathway for delivery of quality indicators on education at the national and international level.

On this pathway, the UIS can provide technical assistance to countries with the objective of developing national statistical capacity for delivering quality data for SDG 4 indicators, working in a cooperative manner on all or specific stages of the production process. The SDG 4 Pilot Initiative of UNESCO's CapED Programme is putting into practice this approach by taking into account the complexities of the monitoring challenges and providing the careful planning needed to improve the production and delivery of the necessary indicators. This must include quality assessments of the existing data sources.

The framework to guide the production of quality data on education presented in this report is well aligned with international, regional and several national data quality assurance frameworks. It relies on establishing specific codes of practice for education-relevant data sources that define quality principles for each of the three broad areas identified in the statistical production processes: the institutional environment, the statistical process itself and the statistical outputs.

The report has identified certain actions that are critical to create the conditions for adequate monitoring of the SDG 4-Education 2030 Agenda. Further work is needed to accelerate support for developing the remaining methodologies and data production standards for those SDG 4 indicators which are not yet being reported. Also, the global coverage of some of the existing SDG 4 indicators is low and many countries are left behind in reporting and monitoring their progress towards the SDG-4 goals. A particularly critical aspect for reporting on the SDGs is measurement of equity across all data sources for education indicators.

All these aspects are at the core of implementation of the SDG 4 monitoring processes. These challenges cannot be addressed without reinforcing the role, responsibility and resources of national governments in the production of quality data. Countries and international organizations need financial assistance to dedicate the expertise and time required to build the foundations of the national and international monitoring systems for the production of effective cross-nationally comparable indicators.

Implementing the SDG 4 monitoring processes also requires significant coordination among the international, regional and national statistical entities involved in collecting and reporting data. At the supra-national level, it is critical to avoid the duplication of efforts, thereby exacerbating the reporting burden imposed on national capacity, and sending contradictory messages from international organizations. At the national level, a sectoral strategy on education, such as the NSDES proposed here, is crucial to articulate the efforts of all country statistical stakeholders and assure an efficient allocation of resources.

The role of financial partners in the success of developing quality monitoring mechanisms cannot be understated. It is essential to mobilise sufficient domestic and external resources by countries and donors to support the efforts of the statistical community. Targeted investments are required to build the foundations of sound and robust national and international statistical systems. No country can be left behind in monitoring progress towards SDG 4. systems. No country can be left behind in monitoring progress towards SDG 4. 


\section{References}

African Union Commission (2015a). Agenda 2063: The Africa We Want (Framework Document). Addis Ababa: African Union. http://www.un.org/en/africa/osaa/pdf/au/agenda2063-framework.pdf

African Union Commission (2015b). Agenda 2063. The Africa We Want: A Shared Strategic Framework for Inclusive Growth and Sustainable Development. First 10-Year Implementation Plan 2014-2023. Addis Ababa: African Union. file://C:/Consulting/UIS\%20-\%20editorial\%20work\%20June\%202017/ References/Agenda_2063_First_Ten_Year_Implementation_Plan_2014_2023_EN.pdf

CCS-UNS (2016). Report of the Committee of the Chief Statisticians of the United Nations System. Note by the Secretary-General (Statistical Commission Forty-eighth session, 7-10 March 2017 No. E/ CN.3/2017/29). New York: Committee of the Chief Statisticians of the United Nations System (CCSUNS). https://unstats.un.org/unsd/statcom/48th-session/documents/2017-29-UNSystem-E.pdf

CCS-UNS (2017). Draft UN Statistics Quality Assurance Framework Including a Generic Statistical Quality Assurance Framework for a UN Agency (Statistical Commission Forty-Eighth Session, 7-10 March 2017). New York: Committee of the Chief Statisticians of the United Nations System (CCS-UNS). https://unstats.un.org/unsd/statcom/48th-session/documents/BG-4j-QAF-E.pdf

DANE (2017). Plan Estadístico Nacional 2017 - 2022 Documento aprobado y expedido por el Consejo Asesor Nacional de estadística, 27 de abril de 2017. Bogotá: Departamento Administrativo Nacional de Estadística (DANE). https://www.dane.gov.co/files/sen/PEN-2017-2022.pdf

ECLAC (2011a). Code of Good Practice in Statistics for Latin America and the Caribbean (sixth meeting of the Statistical Conference of the Americas of the Economic Commission for Latin America and the Caribbean in Bávaro, Dominican Republic, 16-18 November 2011). Santiago: United Nations Economic Commission for Latin America and the Caribbean (ECLAC). http://www.dane.gov.co/files/noticias/ BuenasPracticas_en.pdf

ECLAC (2011b). Proposal for a Code of Good Practice in Statistics in Latin America and the Caribbean and Implementation Plan for 2012-2013 (sixth meeting of the Statistical Conference of the Americas of the Economic Commission for Latin America and the Caribbean Bávaro, Dominican Republic 16-18 November 2011). Santiago: United Nations Economic Commission for Latin America and the Caribbean (ECLAC). http://repositorio.cepal.org/bitstream/handle/11362/16393/1/S1100683_en.pdf

ESS (2015). Quality Assurance Framework of the European Statistical System (No. Version 1.2). Luxembourg: European Union. European Statistical System (ESS). http://ec.europa.eu/eurostat/ documents/64157/4392716/ESS-QAF-V1-2final.pdf/bbf5970c-1adf-46c8-afc3-58ce177a0646

Eurostat (2011). European Statistics Code of Practice for the National and Community Statistical Authorities (Adopted by the European Statistical System Committee). Luxembourg: European Commission, EUROSTAT Directorate. http://ec.europa.eu/eurostat/web/quality/european-statisticscode-of-practice

Eurostat (2017). Indicators for Monitoring the Sustainable Development Goals (SDGs) in an EU Context. EU SDG Indicator Set Final version of 28 April 2017 as agreed with Commission Services, which received a favourable opinion by the European Statistical System Committee at its meeting of 17-18 May 2017. Luxembourg: European Commission, EUROSTAT Directorate E: Sectoral and Regional Statistics Unit E-2: Environmental statistics and accounts; sustainable development. http://ec.europa. eu/eurostat/documents/276524/7736915/EU-SDG-indicator-set-with-cover-note-170531.pdf

Expert Group on National Quality Assurance Frameworks (2012). Glossary. New York, NY: UNSD. https:// unstats.un.org/unsd/dnss/docs-nqaf/NQAF\%20GLOSSARY.pdf 
HLG-PCCB (2017). Cape Town Global Action Plan for Sustainable Development Data. Cape Town, South Africa: High-Level Group for Partnership, Coordination and Capacity-Building for statistics for the 2030 Agenda for Sustainable Development (HLG-PCCB). https://unstats.un.org/sdgs/hlg/Cape-TownGlobal-Action-Plan/

IAEG-MDG (2013). Lessons Learned from MDG Monitoring From A Statistical Perspective Report of the Task Team on Lessons Learned from MDG Monitoring of the IAEG-MDG. New York: United Nations Inter-Agency and Expert Group on MDG Indicators (IAEG-MDG). https://unstats.un.org/unsd/ broaderprogress/pdf/Lesson\%20Learned\%20from\%20MDG\%20Monitoring_2013-03-22\%20(IAEG). pdf

IAEG-SDGs (2016). General principles for refining the indicator framework. Draft - 20 September 2016 (Background document for the 4th meeting of the IAEG-SDGs, 20 - 21 October in Addis Ababa, Ethiopia). New York: Inter-Agency and Expert Group on Sustainable Development Goals Indicators (IAEG-SDGs). https://unstats.un.org/sdgs/files/meetings/iaeg-sdgs-meeting-04/General\%20 Principles\%20for\%20Refining\%20the\%20Indicator\%20Framework.pdf

IMF (2012). Data Quality Assessment Framework. Washington, DC: International Monetary Fund. http:// dsbb.imf.org/pages/dqrs/DQAF.aspx

Keijzer, N. and Klingebiel, S. (2017). Realising the Data Revolution for Sustainable Development: Towards Capacity Development 4.0 (Discussion Paper No. 9). Paris: Partnership in Statistics for Development in the 21st Century (PARIS21).

Montoya, S. and Hastedt, D. (2017). "News from Hamburg: Big Steps Forward Towards Reliable Metrics to Harmonise Learning Assessment Data Globally", UIS Data Blog. http://www.norrag.org/newshamburg-big-steps-forward-towards-reliable-metrics-harmonise-learning-assessment-data-globallysilvia-montoya-dirk-hastedt/

Montoya, S. and Naidoo, J. (2017). "Moving up a Gear: The CapED Initiative”, UIS Data Blog. https://sdg. uis.unesco.org/2017/08/02/moving-up-a-gear-the-caped-initiative/

PARIS21 (2017). Sectoral strategies for the Development of Statistics (SSDS) - NSDS Guidelines. Paris: Partnership in Statistics for Development in the 21st Century (PARIS21). http://nsdsguidelines.paris21. org/node/292

TCG (2017). Agreement on indicators to monitor progress towards SDG 4 in 2017: Table 1 (Result of the Second TCG Meeting, Madrid, 28 October 2016). Madrid: Technical Cooperation Group for SDG 4-Education 2030 (TCG). http://uis.unesco.org/sites/default/files/documents/tcg-thematiceducation-indicators-final.xlsx

UN (2000). United Nations Millennium Declaration (No. A/RES/55/2). New York: United Nations. http:// www.un.org/millennium/declaration/ares552e.pdf (Accessed 7 September 2017).

UN (2014). Fundamental Principles of Official Statistics (Resolution A/68/L.36, General Assembly, 29 January 2014). New York: United Nations. https://unstats.un.org/unsd/dnss/gp/FP-New-E.pdf

UN (2015). Transforming our World: The 2030 Agenda for Sustainable Development. New York: United Nations. https://sustainabledevelopment.un.org/post2015/transformingourworld/publication

UN (2017). High-Level Political Forum on Sustainable Development. https://sustainabledevelopment. un.org/hlpf (Accessed 7 September 2017).

UNCTAD and Task Team (2016). United Nations Statistics Quality Assurance Framework (UNSQAF) Including a Generic Statistical Quality Assurance Framework for a UN Agency (No. UNSYSTEM/2017/3). New York: United Nations Conference on Trade and Development. https:// unstats.un.org/unsd/unsystem/Documents-March2017/UNSystem-2017-3-QAF.pdf 
UNDESA (2016). Progress Towards the Sustainable Development Goals. New York: United Nations Department of Economic and Social Affairs (UNDESA). https://unstats.un.org/sdgs/files/report/2016/ secretary-general-sdg-report-2016--EN.pdf

UNDESA (2017). High-Level Political Forum Timeline. https://sustainabledevelopment.un.org/hlpf (Accessed 7 September 2017).

UNESCO (2000). The Dakar Framework for Action. Education for All: Meeting our Collective Commitments. Including Six Regional Frameworks for Action. Adopted by the World Education Forum. Dakar, 26-28 April. Paris: UNESCO.

UNESCO (2015). Education 2030 Incheon Declaration and Framework for Action Towards inclusive and equitable quality education and lifelong learning for all (No. ED-2016/WS/2). Paris: UNESCO.

UNESCO (2016). The CapED Annual Report 2016. Paris: UNESCO.

UNESCO (2017). Revised Medium-Term Strategy 2017-2021 of the UNESCO Institute for Statistics (UNESCO Executive Board 201st session, Item 13 of the provisional agenda No. 201 EX/13). Paris: UNESCO.

UNESCO Institute for Statistics (UIS) (2012a). International Standard Classification of Education ISCED 2011. Montréal: UNESCO Institute for Statistics (UIS).

UNESCO Institute for Statistics (UIS) (2012b). Ed-DQAF Wiki. http://dqaf.uis.unesco.org/index. php?title=Main_Page (Accessed 7 September 2017).

UNESCO Institute for Statistics (UIS) (2014). ISCED Fields of Education and Training 2013 (ISCED-F 2013) (Manual to accompany the International Standard Classification of Education 2011). Montréal: UNESCO Institute for Statistics (UIS). http://uis.unesco.org/sites/default/files/documents/isced-fieldsof-education-and-training-2013-en.pdf

UNESCO Institute for Statistics (UIS) (2016). Laying the Foundation to Measure Sustainable Development Goal 4 (Sustainable Development Data Digest). Montréal: UNESCO Institute for Statistics (UIS). http:// uis.unesco.org/sites/default/files/documents/laying-the-foundation-to-measure-sdg4-sustainabledevelopment-data-digest-2016-en.pdf

UNESCO Institute for Statistics (UIS) (2017a). Capacity development tools. Montréal: UNESCO Institute for Statistics (UIS). http://uis.unesco.org/en/capacity-development-tools (Accessed 7 September 2017).

UNESCO Institute for Statistics (UIS) (2017b). Ed-Data Quality Assessment Framework (Ed-DQAF) to Evaluate Administrative Routine Data Systems: Training Workshop Manual. Montréal: UNESCO Institute for Statistics (UIS).

UNESCO Institute for Statistics (UIS) (2017c). Education dataset. http://data.uis.unesco.org/ (Accessed 1 June 2017).

UNESCO Institute for Statistics (UIS) (2017d). Light Data Quality Assessment Framework: Government Education Expenditure Data Sources. Montréal: UNESCO Institute for Statistics (UIS). http://uis. unesco.org/en/search/site/data\%20quality\%20assessment\%20framework\%20light\%20administrative ?f\%5B0\%5D=type\%3Adocument

UNESCO Institute for Statistics (UIS) (2017e). Metadata for the Global and Thematic Indicators for the Follow-Up and Review of SDG 4 and Education 2030. Montréal: UNESCO Institute for Statistics (UIS). http://uis.unesco.org/sites/default/files/documents/sdg4-metatdata-global-thematic-indicators.pdf 
UNESCO Institute for Statistics (UIS) (2017f). More Than One-Half of Children and Adolescents Are Not Learning Worldwide (Fact Sheet No. 46). Montréal: UNESCO Institute for Statistics (UIS). http://uis. unesco.org/sites/default/files/documents/fs46-more-than-half-children-not-learning-en-2017.pdf

UNESCO Institute for Statistics (UIS) (2017g). Rapid Data Quality Assessment for Pacific Island Countries. https://docs.google.com/forms/d/e/1FAlpQLSes2Bglll2fe-0cgR1p9GFhErhzZd4GbVYNZ5WAAwhI5IWRw/viewform?c=0\&w=1 (Accessed 7 September 2017).

UNESCO Institute for Statistics (UIS) (2017h). SDG Data Reporting Proposal of a Protocol for Reporting Indicator 4.1.1. Montréal: UNESCO Institute for Statistics (UIS). http://uis.openplus.ca/gaml/files/ meeting4/Reporting_indicator_4.1.1.pdf

UNESCO Institute for Statistics (UIS) (2017i). The Data Revolution in Education (Information Paper No. 39). Montréal: UNESCO Institute for Statistics (UIS).

UNESCO Institute for Statistics (UIS) (2017j). UIS Indicator Development in the Field of Education (Information Paper No. 45). Montréal: UNESCO Institute for Statistics (UIS). http://uis.unesco.org/sites/ default/files/documents/ip45-indicator-development-education-methodology-2017-en.pdf

UNESCO Institute of Statistics (UIS) (forthcoming). Code of Practice for Ministries of Education in Charge of Statistics Produced and Disseminated through Administrative Routine Data Systems. Montréal: UNESCO Institute of Statistics (UIS).

UNESCO Institute for Statistics (UIS) and ACER (2017). Principles of Good Practice in Learning Assessment. Montréal: UNESCO Institute for Statistics (UIS) and Australian Council for Educational Research (ACER). http://uis.unesco.org/sites/default/files/documents/principles-good-practicelearning-assessments-2017-en.pdf

UNESCO Institute for Statistics (UIS) and ACER (forthcoming). SDG 4 Reporting: Data Alignment Process. Montréal: UNESCO Institute for Statistics (UIS).

UNGA (2014). Fundamental Principles of Official Statistics (Fundamental Principles of National Official Statistics No. A/RES/68/261). New York: United Nations General Assembly (UNGA). https://unstats. un.org/unsd/dnss/gp/fundprinciples.aspx (Accessed 7 September 2017).

UNSD (2012). National Quality Assurance Framework. New York: United Nations Statistics Division (UNSD). https://unstats.un.org/unsd/dnss/docs-nqaf/GUIDELINES\%208\%20Feb\%202012.pdf (Accessed 9 September 2017).

UNSD (2013). Principles Governing International Statistical Activities. New York: United Nations Statistics Division (UNSD). https://unstats.un.org/unsd/methods/statorg/Principles_stat_activities/principles_ stat_activities.pdf (Accessed 7 September 2017).

UNSG (2014). "The road to dignity by 2030: ending poverty, transforming all lives and protecting the planet", synthesis report of the Secretary-General on the post-2015 sustainable development agenda (No. A/69/700). New York: United Nations Secretary-General (UNSG). http://www.un.org/ga/search/ view_doc.asp?symbol=A/69/700\&Lang=E (Accessed 7 September 2017).

UNSG (2016). Report of the Inter-Agency and Expert Group on Sustainable Development Goal Indicators (Statistical Commission forty-seventh session, 8-11 March 2016 Item 3 (a) of the provisional agenda. Items for discussion and decision: data and indicators for the 2030 Sustainable Development Agenda No. E/CN.3/2016/2/Rev.1*). New York: United Nations Secretary-General (UNSG) and UN Economic and Social Council (ECOSOC). http://undocs.org/E/CN.3/2016/2/Rev.1 


\section{Annex 1. UIS Code of Practice for education statistics: Principles and indicators}

\section{Institutional environment}

Institutional and organizational factors have a significant influence on the effectiveness and creditability of ministries of education developing, producing and disseminating education statistics.

\section{Principle 1: Policy and legal framework.} Legal and institutional environment governing education statistics have a significant influence on the effectiveness and credibility of a ministry of education to produce and disseminate education statistics.

1.1: The responsibility for collecting, processing, and disseminating statistics is clearly specified.

1.2: Data sharing and coordination among agencies producing education data are adequate.

1.3: Respondents' data are to be kept confidential and used for statistical purposes only.

1.4: Statistical reporting is ensured through legal mandate and/or measures to encourage response.

Principle 2. Adequacy of resources. The ministry of education ensures that resources are commensurate with the statistical programmes, personnel, facilities, equipment, technology, training and financing of their education management information systems.

2.1: Staff, financial, and computing resources are commensurate with statistical programmes of the ministry of education.

\section{2: Measures to ensure efficient use of resources are implemented.}

Principle 3. Quality awareness. Quality is a cornerstone of statistical work. Ministries of education systematically and regularly identify strengths and weaknesses to continuously improve process and product quality.

\section{1: Processes are in place to focus on quality.}

3.2: Managers give due consideration to monitor the quality of the collection, processing, and dissemination of statistics.

3.3: Managers deal with quality considerations in planning the statistical programme.

Principle 4. Professionalism. Statistical policies and practices are guided by professional principles.

4.1: Statistics are compiled on an impartial basis.

4.2: Choices of sources and statistical techniques are informed solely by statistical considerations.

4.3: The appropriate statistical entity is entitled to comment on erroneous interpretation and misuse of statistics.

Principle 5. Transparency. Ministries of education develop, produce and disseminate education statistics in an objective, and transparent manner in which all users are treated equitably.

5.1: The terms and conditions under which statistics are collected, processed, and disseminated are available to the public.

5.2: Internal governmental access to statistics prior to their release is publicly identified.

5.3: Products of statistical agencies/units are clearly identified as such.

5.4: Advance notice is given of major changes in methodology, source data, and statistical techniques.

Principle 6. Ethical standards. Policies and practices are guided by ethical standards.

6.1: Guidelines for staff behaviour are in place and are well known to the staff. 


\section{Statistical Processes}

International standards, guidelines and good practices are fully observed in the processes used by the ministries to organize, collect, process and disseminate official statistics. The credibility of the statistics is enhanced by a reputation for good management and efficiency.

Principle 7. Sound methodology. The methodological basis for education statistics follows internationally-accepted standards, guidelines or good practices.

7.1: Concepts and definitions used are in accord with standard statistical frameworks.

7.2: The scope is in accord with internationallyaccepted standards, guidelines or good practices.

7.3: Classification systems are in accord with national and internationally-accepted standards, guidelines or good practices.

7.4: Data are recorded according to internationally-accepted standards, guidelines or good practices.

Principle 8. Accuracy and reliability. Data sources and statistical techniques are sound and education statistical outputs sufficiently portray reality.

8.1: Available data sources provide an adequate basis to compile statistics.

8.2: Data sources are regularly assessed and validated.

8.3: Statistical techniques employed conform to sound statistical procedures and are documented.

8.4: Revisions, as a gauge of reliability, are tracked and mined for the information they may provide.

8.5: Source data and statistical results are archived.

\section{Education statistical outputs}

Available statistics meet users' needs. Education statistics comply with international quality standards and serve the needs of international institutions, governments, research institutions, business concerns and the public generally.
Principle 9. Relevance. Education statistics meet the needs of users.

9.1: Consultations with data's users are done periodically.

9.2: Priority needs are being met and reflected in the work programme.

9.3: User satisfaction is monitored on a regular basis and is systematically followed up.

\section{Principle 10. Periodicity and timeliness.}

Education statistics are released following internationally-accepted periodicity and in a timely manner.

10.1: Periodicity follows dissemination standards.

10.2: Timeliness follows dissemination standards.

10.3: A calendar of publication is made available and deviation from the dissemination schedule is publicised.

Principle 11. Consistency. Released education statistics are consistent within a dataset and over time, and with other major datasets.

11.1: Final statistics are consistent within a dataset.

11.2: Final statistics are consistent or reconcilable over a reasonable period of time.

11.3: Final statistics are consistent or reconcilable with those obtained through other surveys and data sources.

Principle 12. Accessibility and clarity. Education statistics and metadata are easily available in a clear and understandable manner, and there is adequate user support.

12.1: Statistics are presented in a clear and understandable manner, forms of dissemination are adequate, and statistics are made available on an impartial basis.

12.2: Up-to-date and pertinent metadata are made available.

12.3: Prompt and knowledgeable assistance support service to users is available. 


\section{Annex 2. Links between the UIS Code of Practice for education statistics and the UN National Quality Assurance Framework (NQAF)}

Institutional environment: Institutional and organizational factors have a significant influence on the effectiveness and creditability of ministries of education developing, producing and disseminating education statistics. The relevant aspects are a policy and legal framework, adequacy of resources, quality awareness, professionalism, transparency and ethical standards.

\section{Prerequisites of quality}

The institutional environment guarantees the effectiveness of fundamental principles of official statistics.

Principle 1: Policy and legal framework. The legal and institutional environment governing education statistics has a significant influence on the effectiveness and credibility of a ministry of education to produce and disseminate education statistics.
NQAF01. Coordinating the national statistical system NQAF07. Assuring statistical confidentiality and security NQAF13. Managing the respondent burden

Principle 2: Adequacy of resources. The ministry of education ensures that resources are commensurate with the statistical programmes, personnel, facilities, equipment, technology, training and financing of their education management information systems.

Principle 3: Quality awareness. Quality is a cornerstone of statistical work. Ministries of education systematically and regularly identify strengths and weaknesses to continuously improve process and product quality.

NQAF09. Assuring adequacy of resources NQAF11. Assuring cost effectiveness

\section{Assurances of integrity}

The principle of objectivity in the collection, processing, and dissemination of statistics is firmly adhered to.

Principle 4: Professionalism. Statistical policies and practices are guided by professional principles.

NQAF05. Assuring impartiality and objectivity NQAF04. Assuring professional independence

Principle 5: Transparency. Ministries of education develop, produce and disseminate education statistics in an objective, and transparent manner in which all users are treated equitably.

Principle 6: Ethical standards. Policies and practices are guided by ethical standards.

NQAF05. Assuring impartiality and objectivity 
Statistical processes: International standards, guidelines and good practices are fully observed in the processes used by the ministries to organize, collect, process and disseminate official statistics. The credibility of the statistics is enhanced by a reputation for good management and efficiency. The relevant aspects are methodological soundness, accuracy and reliability.

\section{Methodological soundness}

The methodological basis for the statistics follows internationally-accepted standards, guidelines or good practices.

Principle 7: Sound methodology. The methodological basis for the education statistics follows internationally-accepted standards, guidelines or good practices.
NQAF10. Assuring methodological soundness

\section{Accuracy and reliability}

Source data and statistical techniques are sound and statistical outputs sufficiently portray reality

Principle 8: Accuracy and reliability. Data sources and statistical techniques are sound and education statistical outputs sufficiently portray reality.
NQAF03. Managing statistical standards NQAF15. Assuring accuracy and reliability NQAF12. Assuring soundness of implementation NQAF15. Assuring accuracy and reliability NQAF17. Assuring accessibility and clarity

Education statistical outputs: Available statistics meet users' needs. Education statistics comply with the international quality standards and serve the needs of international institutions, governments, research institutions, business concerns and the public generally. The important issues concern relevance, periodicity and timeliness, consistency and accessibility, and clarity.

\section{Serviceability}

Statistics are relevant and with adequate periodicity and timeliness, are consistent and follow a predictable revisions policy.

Principle 9: Relevance. Education statistics meet the needs of users.

NQAF14. Assuring relevance

NQAF16. Assuring timeliness and punctuality released following internationally-accepted periodicity and in a timely manner.

Principle 11: Consistency. Released education statistics are consistent within a dataset and over time, and with other major datasets.

\section{Accessibility}

Data and metadata are easily available and assistance to users is adequate.

Principle 12: Accessibility and clarity. Education statistics and metadata are easily available in a clear and understandable manner, and there is adequate user support.
NQAF17. Assuring accessibility and clarity NQAF02. Managing relationships with data users and data providers

Note: Principles used in the UN's NQAF are shaded. 


\section{Annex 3. National capacity development implementation strategies}

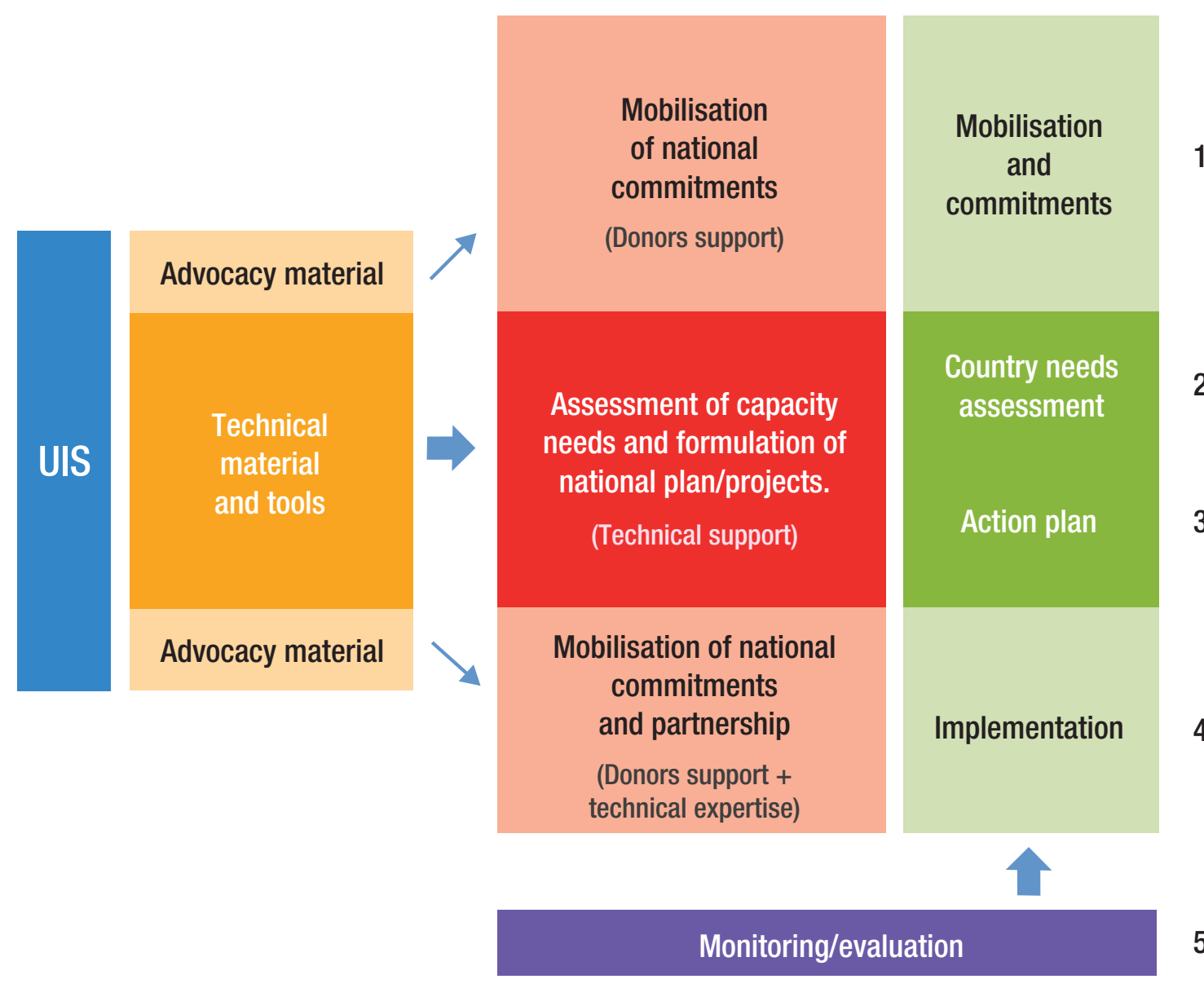




\section{Annex 4. SDG 4 targets by data source}

\begin{tabular}{|c|c|c|c|c|}
\hline \multirow[b]{2}{*}{ Targets } & \multicolumn{4}{|c|}{ Data source } \\
\hline & $\begin{array}{l}\text { Adminis- } \\
\text { trative }\end{array}$ & Finance & $\begin{array}{l}\text { Household } \\
\text { survey }\end{array}$ & $\begin{array}{l}\text { Learning } \\
\text { outcomes } \\
\text { assessment }\end{array}$ \\
\hline $\begin{array}{l}\text { Target } 4.1 \text { By } 2030 \text {, ensure that all girls and boys complete free, } \\
\text { equitable and quality primary and secondary education leading to } \\
\text { relevant and effective learning outcomes }\end{array}$ & 4 & & 3 & 1 \\
\hline $\begin{array}{l}\text { Target } 4.2 \text { By } 2030 \text {, ensure that all girls and boys have access to } \\
\text { quality early childhood development, care and pre-primary education } \\
\text { so that they are ready for primary education }\end{array}$ & 3 & & 4 & 1 \\
\hline $\begin{array}{l}\text { Target } 4.3 \text { By } 2030 \text {, ensure equal access for all women and men to } \\
\text { affordable quality technical, vocational and tertiary education, including } \\
\text { university }\end{array}$ & 3 & & 3 & \\
\hline $\begin{array}{l}\text { Target } 4.4 \text { By } 2030 \text {, substantially increase the number of youth and } \\
\text { adults who have relevant skills, including technical and vocational } \\
\text { skills, for employment, decent jobs and entrepreneurship }\end{array}$ & & & 3 & 1 \\
\hline $\begin{array}{l}\text { Target } 4.5 \text { By } 2030 \text {, eliminate gender disparities in education and } \\
\text { ensure equal access to all levels of education and vocational training } \\
\text { for the vulnerable, including persons with disabilities, indigenous } \\
\text { peoples and children in vulnerable situations }\end{array}$ & 3 & 2 & 1 & \\
\hline $\begin{array}{l}\text { Target } 4.6 \text { By 2030, ensure that all youth and a substantial proportion } \\
\text { of adults, both men and women, achieve literacy and numeracy }\end{array}$ & 1 & & 3 & 1 \\
\hline $\begin{array}{l}\text { Target } 4.7 \text { By 2030, ensure all learners acquire knowledge and skills } \\
\text { needed to promote sustainable development, including among others } \\
\text { through education for sustainable development and sustainable } \\
\text { lifestyles, human rights, gender equality, promotion of a culture of } \\
\text { peace and non-violence, global citizenship, and appreciation of cultural } \\
\text { diversity and of culture's contribution to sustainable development }\end{array}$ & 3 & & & 2 \\
\hline $\begin{array}{l}\text { Target 4.a Build and upgrade education facilities that are child, } \\
\text { disability and gender sensitive and provide safe, non-violent, inclusive } \\
\text { and effective learning environments for all }\end{array}$ & 1 & & 1 & \\
\hline $\begin{array}{l}\text { Target 4.b By 2020, substantially expand globally the number of } \\
\text { scholarships available to developing countries, in particular least } \\
\text { developed countries, small island developing States and African } \\
\text { countries, for enrolment in higher education, including vocational } \\
\text { training, information and communications technology, technical, } \\
\text { engineering and scientific programmes in developed countries and } \\
\text { other developing countries }\end{array}$ & 2 & & & \\
\hline $\begin{array}{l}\text { Target 4.c By 2030, substantially increase the supply of qualified } \\
\text { teachers, including through international cooperation for teacher } \\
\text { training in developing countries, especially least developed countries } \\
\text { and small island developing States }\end{array}$ & 7 & & 1 & \\
\hline TOTAL SDG 4 & 27 & 2 & 19 & 6 \\
\hline
\end{tabular}




\section{Annex 5. Twelve main questions to assess the data quality of government financial systems}

\begin{tabular}{|c|c|c|}
\hline \multicolumn{3}{|r|}{ Principle 3: Relevance } \\
\hline \multirow{2}{*}{$\begin{array}{l}\text { Institutional } \\
\text { environment }\end{array}$} & 1 & $\begin{array}{l}\text { Data users from the education sector are systematically consulted or kept informed } \\
\text { on aspects of government finance data which are of relevance to their sector (e.g. } \\
\text { classification, periodicity, timeliness). }\end{array}$ \\
\hline & 2 & $\begin{array}{l}\text { The production of education financing data is coordinated among the various ministries (at } \\
\text { central, regional and local levels) and agencies involved in the funding of education. }\end{array}$ \\
\hline \multicolumn{3}{|r|}{ Principle 4: Sound methodology } \\
\hline \multirow{7}{*}{$\begin{array}{l}\text { Statistical } \\
\text { processes }\end{array}$} & 3 & $\begin{array}{l}\text { Government finance data collection and publication processes cover all levels of } \\
\text { government (central, regional and local) within a centralised data system. }\end{array}$ \\
\hline & 4 & $\begin{array}{l}\text { Government financial data include a functional classification (by sector such as education, } \\
\text { and not only by Ministry or agency), including education by levels. }\end{array}$ \\
\hline & 5 & $\begin{array}{l}\text { Government financial data include a disaggregation by nature of expenditure, including } \\
\text { teaching and non-teaching staff compensation, expenditure on school books and teaching } \\
\text { materials, student loans and scholarships, and government support to private schools. }\end{array}$ \\
\hline & 6 & $\begin{array}{l}\text { Government financial data include detailed funding by foreign donors which are 'on } \\
\text { budget'. }\end{array}$ \\
\hline & 7 & $\begin{array}{l}\text { There is an accessible and usable data source for foreign donor projects (including those } \\
\text { not recorded in the government budget). }\end{array}$ \\
\hline & 8 & There is one unified and recognised source of data on government expenditure. \\
\hline & 9 & $\begin{array}{l}\text { Government financial data are classified according to the Government Financial Statistics } \\
\text { (GFS) manual or a regional classification of government expenses. }\end{array}$ \\
\hline \multicolumn{3}{|r|}{ Principle 6: Periodicity and timeliness } \\
\hline \multirow{2}{*}{ Statistical outputs } & 10 & $\begin{array}{l}\text { Education expenditure data are available for budget and actual expenditure for the } \\
\text { previous financial year. }\end{array}$ \\
\hline & 11 & Internationally-comparable data on education financing are reported in a timely manner. \\
\hline \multicolumn{3}{|r|}{ Principle 8: Accessibility and clarity } \\
\hline Statistical outputs & 12 & $\begin{array}{l}\text { Government education financing data are disseminated and/or made available to } \\
\text { ministries of education in a manner that facilitates their access (e.g. online, access to a } \\
\text { database). }\end{array}$ \\
\hline
\end{tabular}

Source: UNESCO Institute for Statistics (2017d). 


Countries are struggling to respond to the unprecedented demand for more and better data associated with the 2030 Agenda for Sustainable Development. In education, the international community has agreed to use a set of 11 global indicators and 32 thematic indicators to monitor progress towards Sustainable Development Goal (SDG) 4. Yet the challenge to produce them is enormous. According to the world's most comprehensive global education database - produced by the UNESCO Institute for Statistics (UIS) - less than half of countries are currently reporting 19 global and thematic indicators and only 1 global indicator and 6 thematic indicators have coverage exceeding $75 \%$.

As the official data source for SDG 4-Education 2030, the UIS works on a daily basis with national statistical offices and ministries of education around the world to collect the data and apply the standards and methodologies needed to produce cross-nationally comparable indicators. The Institute understands the challenges facing national statisticians and is therefore uniquely placed to help countries strengthen their statistical capacities.

This report presents a comprehensive strategy and framework to improve the quality of data needed to implement and monitor progress towards the SDG 4-Education 2030 Agenda. It showcases a concrete set of tools designed to help countries strengthen each stage of their national education statistical systems - from diagnostic tools to evaluate data availability and quality to the frameworks and guidelines needed to initiate a national strategy for the development of education statistics that directly responds to policy priorities. The report also addresses the wider statistical capacity-development issues facing countries, donors and partners. Above all, the UIS shows the way forward to building better statistical systems by providing national stakeholders with the tools and strategies they need to produce high-quality education data and achieve their development goals.
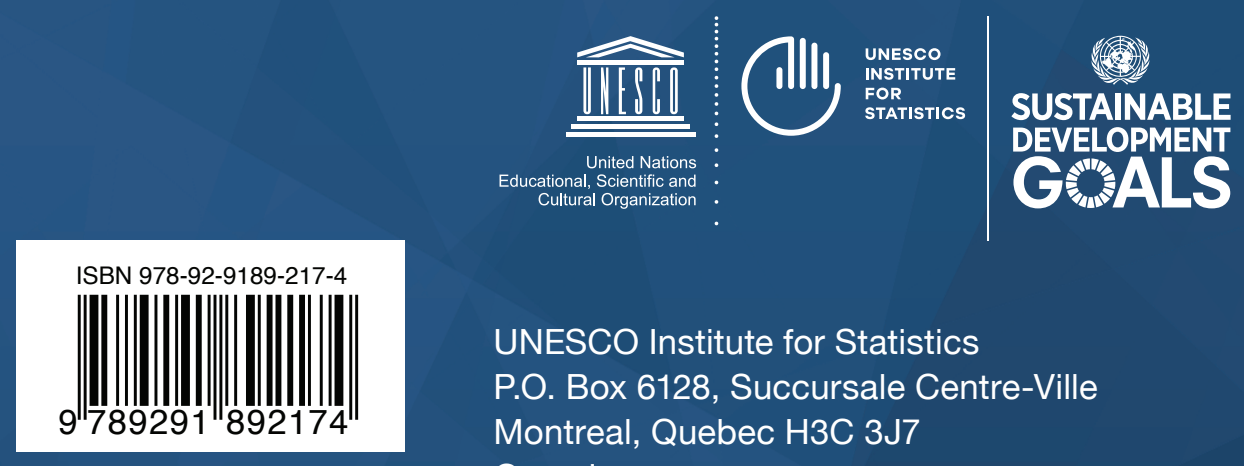

UNESCO Institute for Statistics

P.O. Box 6128, Succursale Centre-Ville

Montreal, Quebec H3C 3J7

Canada 